\title{
Secondary organic aerosol formation exceeds primary particulate matter emissions for light-duty gasoline vehicles
}

\author{
T. D. Gordon ${ }^{1,2, *, * *}$, A. A. Presto ${ }^{1}$, A. A. May ${ }^{1, * * *}$, N. T. Nguyen ${ }^{1}$, E. M. Lipsky ${ }^{3}$, N. M. Donahue ${ }^{1,2}$, A. Gutierrez ${ }^{4}$, \\ M. Zhang ${ }^{4}$, C. Maddox $^{5}$, P. Rieger ${ }^{5}$, S. Chattopadhyay ${ }^{6}$, H. Maldonado ${ }^{7}$, M. M. Maricq ${ }^{8}$, and A. L. Robinson ${ }^{1,2}$ \\ ${ }^{1}$ Center for Atmospheric Particle Studies, Carnegie Mellon University, Pittsburgh, PA 15213, USA \\ ${ }^{2}$ Engineering and Public Policy, Carnegie Mellon University, Pittsburgh, PA 15213, USA \\ ${ }^{3}$ Department of Engineering, Penn State Greater Allegheny, McKeesport, PA 15131, USA \\ ${ }^{4}$ Mobile Source Operations, California Air Resources Board, El Monte, CA 91731, USA \\ ${ }^{5}$ Monitoring and Laboratory, California Air Resources Board, El Monte, CA 91731, USA \\ ${ }^{6}$ Planning and Technical Support, California Air Resources Board, El Monte, CA 91731, USA \\ ${ }^{7}$ Research Division, California Air Resources Board, Sacramento, CA 95814, USA \\ ${ }^{8}$ Research and Advanced Engineering, Ford Motor Company, Dearborn, MI 48120, USA \\ *now at: National Oceanic and Atmospheric Administration Earth System Research Laboratory, Chemical Sciences Division, \\ 325 Broadway, Boulder, CO 80305, USA \\ ** now at: Cooperative Institute for Research in Environmental Sciences, University of Colorado, 216 UCB, Boulder, CO \\ 80309, USA \\ *** now at: Department of Atmospheric Science, Colorado State University, Fort Collins, CO 80523, USA
}

Correspondence to: A. Robinson (alr@andrew.cmu.edu)

Received: 1 August 2013 - Published in Atmos. Chem. Phys. Discuss.: 4 September 2013

Revised: 26 February 2014 - Accepted: 4 March 2014 - Published: 13 May 2014

\begin{abstract}
The effects of photochemical aging on emissions from 15 light-duty gasoline vehicles were investigated using a smog chamber to probe the critical link between the tailpipe and ambient atmosphere. The vehicles were recruited from the California in-use fleet; they represent a wide range of model years (1987 to 2011), vehicle types and emission control technologies. Each vehicle was tested on a chassis dynamometer using the unified cycle. Dilute emissions were sampled into a portable smog chamber and then photochemically aged under urban-like conditions. For every vehicle, substantial secondary organic aerosol (SOA) formation occurred during cold-start tests, with the emissions from some vehicles generating as much as 6 times the amount of SOA as primary particulate matter (PM) after $3 \mathrm{~h}$ of oxidation inside the chamber at typical atmospheric oxidant levels (and 5 times the amount of SOA as primary PM after $5 \times 10^{6}$ molecules $\mathrm{cm}^{-3} \mathrm{~h}$ of $\mathrm{OH}$ exposure). Therefore, the contribution of light-duty gasoline vehicle exhaust to ambient PM levels is likely dominated by secondary PM production (SOA and nitrate). Emissions from hot-start tests formed
\end{abstract}

about a factor of 3-7 less SOA than cold-start tests. Therefore, catalyst warm-up appears to be an important factor in controlling SOA precursor emissions. The mass of SOA generated by photooxidizing exhaust from newer (LEV2) vehicles was a factor of 3 lower than that formed from exhaust emitted by older (pre-LEV) vehicles, despite much larger reductions (a factor of 11-15) in nonmethane organic gas emissions. These data suggest that a complex and nonlinear relationship exists between organic gas emissions and SOA formation, which is not surprising since SOA precursors are only one component of the exhaust. Except for the oldest (pre-LEV) vehicles, the SOA production could not be fully explained by the measured oxidation of speciated (traditional) SOA precursors. Over the timescale of these experiments, the mixture of organic vapors emitted by newer vehicles appears to be more efficient (higher yielding) in producing SOA than the emissions from older vehicles. About $30 \%$ of the nonmethane organic gas emissions from the newer (LEV1 and LEV2) vehicles could not be speciated, and the majority of the SOA formed from these vehicles appears to 
be associated with these unspeciated organics. By comparing this study with a companion study of diesel trucks, we conclude that both primary PM emissions and SOA production for light-duty gasoline vehicles are much greater than for late-model (2007 and later) on-road heavy-duty diesel trucks.

\section{Introduction}

Ambient fine particulate matter (PM) is comprised of a complex mixture of constituents, including sulfates, nitrate, ammonium, organic material (organic aerosols), elemental carbon (EC), crustal materials, trace elements, and water. Organic aerosols often contribute a third or more of fine PM mass, but their sources are poorly understood (Kanakidou et al., 2005; Turpin et al., 2000). Primary organic aerosol (POA) is emitted directly "from the tailpipe"; secondary organic aerosol (SOA) is formed in the atmosphere from the oxidation of gaseous precursors. Numerous reports have shown that the secondary fraction of fine organic PM (SOA) dominates POA, even in urban areas with substantial fresh POA emissions (Jimenez et al., 2009; Subramanian et al., 2007; Stone et al., 2009). However, chemical transport models systematically underpredict SOA levels (de Gouw et al., 2005; Heald et al., 2005; Volkamer et al., 2006), especially during photochemical episodes (Vutukuru et al., 2006). Motor vehicle emissions contribute to both POA and SOA concentrations.

Recent smog chamber studies of dilute exhaust from different combustion processes - including diesel generators, medium- and heavy-duty diesel vehicles, biomass burning and jet aircraft - have demonstrated that the mass of SOA generated from the oxidation of vapor emissions often exceeds the mass of POA (Weitkamp et al., 2007; Samy and Zielinska, 2010; Chirico et al., 2010; Miracolo et al., 2011; Hennigan et al., 2011; Gordon et al., 2013a). Therefore, SOA production from gaseous precursors may represent the majority of the contribution from these sources to atmospheric organic fine PM. Although much is known about primary emissions from light-duty gasoline vehicles (LDGVs), there are few published reports on SOA formation from LDGVs (Nordin et al., 2013; Platt et al., 2013). Previous studies employ (1) driving cycles that are not relevant to in-use driving patterns and/or (2) a small sample size (in one study only a single vehicle is used), both of which complicate extrapolation of the results to the in-use vehicle fleet. LDGVs emit a mixture of thousands of organic gases, some of which are known SOA precursors, such as single-ring aromatics, but the complexity of these emissions coupled with uncertainty in SOA formation mechanisms means that the contribution of LDGVs to ambient PM is not well understood.

This paper describes smog chamber experiments conducted to investigate the SOA formation from dilute LDGV exhaust. Experiments were performed on 15 LDGVs re- cruited from the California in-use fleet. The vehicles spanned a range of types, model years and emission standards. The vehicles were operated over cold- and hot-start driving cycles designed to represent typical urban driving patterns. The dilute emissions were injected into a smog chamber and photooxidized to quantify the secondary PM formation. Major goals of these experiments were to understand the fraction of the emissions (yield) that form SOA and to assess the relative importance of primary PM emissions versus SOA formation. The research was conducted as part of a large project investigating the link between tailpipe emissions from mobile sources and ambient PM. Companion papers describe primary emissions from on-road vehicles (May et al., 2014), gas-particle partitioning of POA emissions (May et al., 2013a, b), primary PM emission and SOA formation from off-road gasoline and diesel engines (Gordon et al., 2013b) and SOA production from diesel vehicles (Gordon et al., 2013a).

\section{Materials and methods}

\subsection{Experimental setup and procedure}

Emission characterization and photochemical aging experiments were conducted at the California Air Resources Board's (CARB) Haagen-Smit Laboratory (HSL) in El Monte, California (Pisano et al., 2011). Twenty-nine smog chamber experiments were performed with 15 different LDGVs recruited from the California in-use fleet (model years 1987 to 2011). The fleet was not designed to represent the distribution of vehicles in the current, in-use California fleet; instead, vehicles (from private owners located within 50 miles of HSL) were selected to span a wide range of model years, vehicle types, engine technologies, and emission control technologies. All vehicles were port fuel injected except for one LEV2 vechicle (vehicle ID: LEV2-4), which was an early-generation gasoline direct-injected vehicle. Additional details on the individual vehicles are provided in Table S1 in the Supplement.

For discussion, the vehicles are grouped based on model year: "pre-LEV" vehicles were manufactured prior to 1995 ; "LEV1" vehicles were manufactured between 1995 and 2003; and "LEV2" vehicles were manufactured 2004 or later. In this work, the LEV designation simply refers to a range of model years; it does not refer to the emissions certification standard. For example, some of the LEV1 vehicles were certified as Tier 1 vehicles. The certification standard for each vehicle is listed in Table S1. The smog chamber test fleet was comprised of three pre-LEV, six LEV1, and six LEV2 vehicles. All of the vehicles were operated on the same California commercial summertime gasoline; details of its composition are provided in Tables S2 and S3 in the Supplement.

Figure 1 illustrates the experimental setup. The vehicles were driven on a Clayton (Model AC-48) 48 inch (1.22 m) 


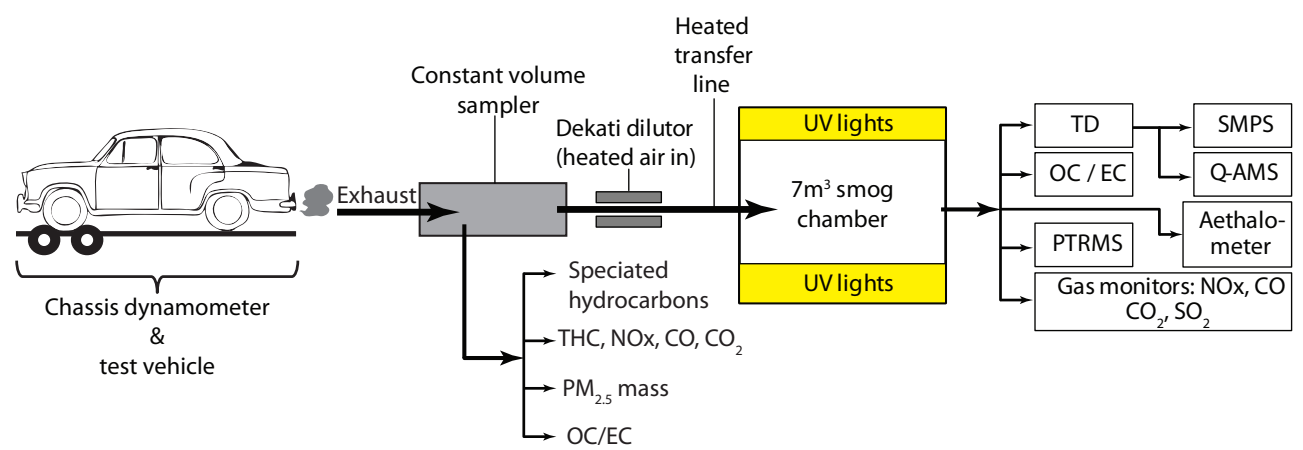

Fig. 1. Experimental setup used to characterize the primary and secondary particulate matter and gas-phase products from motor vehicle emissions. Not to scale. TD = thermodenuder; SMPS = scanning mobility particle sizer; Q-AMS = quadrupole aerosol mass spectrometer; PTRMS = proton transfer reaction mass spectrometer.

single-roll electric chassis dynamometer. Every vehicle was tested using the cold-start Unified Cycle (UC) driving schedule (Fig. S1), which was designed to simulate driving patterns in southern California. It has a three-bag structure similar to the Federal Test Procedure (FTP) but is a more aggressive cycle with higher speeds, higher acceleration, fewer stops per mile, and less idle time (Table S4 in the Supplement). Emissions from vehicles operated over the UC are generally higher than when operated over the FTP (Robert et al., 2007). Four hot-start UC tests were also run (one preLEV, one LEV1 and two LEV2 experiments) to investigate the effects of the temperatures of the engine and emission control system on SOA formation. In the hot-start experiments the vehicle was conditioned by driving over the $5 \mathrm{~min}$ first phase ("bag one") of the UC, after which sampling commenced and the vehicle was immediately driven over the standard three-bag UC.

The entire exhaust flow was sampled using a Horiba constant volume sampling (CVS) system, and the dilute emissions were characterized following CFR (Code of Federal Regulations) Title 40 Part 86 procedures. Gas-phase emissions were measured using an AVL-AMA 4000 system, including total hydrocarbons by flame ionization detection (FID), methane $\left(\mathrm{CH}_{4}\right)$ by FID-gas chromatography (GC), and carbon monoxide $(\mathrm{CO}), \mathrm{NO}_{\mathrm{x}}$ by chemiluminescence and carbon dioxide $\left(\mathrm{CO}_{2}\right)$ by nondispersive infrared (NDIR) detectors. Accuracy, drift $(8 \mathrm{~h})$, noise and linearity for the AVL-AMA 4000 are all within $1 \%$ of full scale, and repeatability is within $0.5 \%$ of full scale. Nonmethane organic gases (NMOG) were calculated from the difference between total hydrocarbons and methane. PM mass emissions were measured by gravimetric analysis of Teflon ${ }^{\circledR}$ membrane filters. Carbonaceous PM emissions were measured using samples collected on pre-fired quartz filters. The quartz filters were analyzed using a Sunset Laboratory Organic Carbon/Elemental Carbon (OC/EC) Analyzer using the IMPROVE-A protocol (Chow et al., 1993). During sampling, the filter trains were maintained at $47 \pm 5^{\circ} \mathrm{C}$.
Comprehensive speciation was performed to quantify emissions of 203 individual organic compounds (see Table S5 in the Supplement). Samples from the CVS were collected in Tedlar ${ }^{\circledR}$ bags and analyzed offline for individual light hydrocarbons $\left(<\mathrm{C}_{5}\right)$ and mid-weight hydrocarbons $\left(\mathrm{C}_{5}\right.$ to $\mathrm{C}_{12}$ ), using standard gas-chromatography-based analytical procedures (California Air Resources Board, 2001, 2004, 2006). Carbonyl emissions were determined from samples collected on 1,4-dinitrophenylhydrazine (DNPH)impregnated cartridges analyzed by high-performance liquid chromatography (http://www.arb.ca.gov/testmeth/slb/ sop104v3.pdf).

Dilute emissions from the CVS were also transferred via an electrically heated $\left(47^{\circ} \mathrm{C}\right)$ 0.5-in-outer-diameter (o.d.) Silcosteel ${ }^{\circledR}$ (i.e., passivated internal bore) stainless steel tubing to a $7 \mathrm{~m}^{3}$ Teflon ${ }^{\circledR}$ smog chamber where they were photochemically aged (Hennigan et al., 2011). Before each experiment the chamber was cleaned by flushing with highefficiency particulate air (HEPA)- and activated-carbonfiltered air overnight. For most experiments (listed in Table S1 in the Supplement), the chamber was seeded to minimize nucleation; approximately $10 \mu \mathrm{g} \mathrm{m}^{-3}$ of ammonium sulfate was injected into the chamber just before the vehicle was started. The smog chamber was located indoors, in a large air-conditioned space; its temperature and relative humidity varied within the ranges of $25-30^{\circ} \mathrm{C}$ and $30-50 \%$. Due to these low relative humidities and the fact that primary vehicle emissions are relatively hydrophobic (Dua et al., 1999; Weingartner et al., 1997), it is unlikely that aqueous SOA formation was important in these experiments.

Vehicle emissions were added to the chamber over the entire UC (but not during the $10 \mathrm{~min}$ hot-soak period); thus, these experiments represent trip-average emissions. The chamber was covered (dark) during filling to prevent photochemistry. During filling, the exhaust was diluted by a factor of 200-300 compared to the tailpipe in three stages: first, it was diluted approximately 10:1 (average over driving cycle) with ambient-temperature HEPA-filtered air in the CVS; it was then diluted another $8-10: 1$ with $47^{\circ} \mathrm{C}$ 
HEPA- and activated-carbon-filtered air using Dekati ejector diluters in the transfer line; finally, it was diluted another 2$3: 1$ with ambient-temperature HEPA- and activated-carbonfiltered air in the smog chamber.

After adding exhaust, HONO (nitrous acid) was introduced into the chamber as an $\mathrm{OH}$ (hydroxyl) radical source by bubbling dry air through a $1: 2$ solution (volume) of $0.1 \mathrm{MNaNO}_{2}$ and $0.05 \mathrm{M} \mathrm{H}_{2} \mathrm{SO}_{4}$ for $\sim 30 \mathrm{~min}$. If necessary, the $\mathrm{VOC} / \mathrm{NO}_{\mathrm{x}}$ ratios were adjusted to approximately $3: 1 \mathrm{ppbC} \mathrm{ppbNO}_{\mathrm{x}}^{-1}$ (typical of many urban environments) by adding propene $(0.0-1.00 \mathrm{ppm})$. In 21 of the 29 experiments $0.06 \mathrm{ppm}$ of deuterated butanol was also injected into the chamber as a hydroxyl radical $(\mathrm{OH})$ tracer. After characterizing the primary emissions in the dark for $\sim 45 \mathrm{~min}$, the emissions were photooxidized by exposing them to UV lights (Model F40BL UVA, General Electric) continuously for $3 \mathrm{~h}$.

A suite of instruments was used to characterize gasand particulate-phase pollutants inside the chamber. Particle number distributions were measured with a scanning mobility particle sizer (SMPS, TSI, Inc., classifier model 3080, CPC model 3772). Nonrefractory submicron aerosol mass and chemical composition were measured with a quadrupole aerosol mass spectrometer (AMS, Aerodyne, Inc.). Gasphase organic species were measured with a proton transfer reaction mass spectrometer (PTR-MS, Ionicon) that was calibrated daily using a custom gas standard from Spectra Gases. Dedicated gas monitors were used to measure $\mathrm{CO}_{2}$ (LI-820, Li-Cor Biosciences), $\mathrm{SO}_{2}, \mathrm{NO}_{\mathrm{x}}, \mathrm{CO}$, and $\mathrm{O}_{3}$ (API-Teledyne Models 100E, 200A, 300A and 400E); monitors were zeroed daily and calibrated at least weekly. A seven-channel Aethalometer (Magee Scientific, Model AE-31) measured black carbon (BC); the Aethalometer data were corrected for particle loading effects using the method of Kirchstetter and Novakov (2007).

It is impossible to exactly reproduce all atmospheric conditions inside a smog chamber. Therefore, we focused on maintaining at urban-like values several key parameters (e.g., $\mathrm{PM}$ concentrations and $\mathrm{VOC} / \mathrm{NO}_{\mathrm{x}}$ ratios) known to strongly influence SOA formation. In most experiments, we added propene (which does not form SOA; Kroll and Seinfeld, 2008) to the chamber to adjust the $\mathrm{VOC} / \mathrm{NO}_{\mathrm{x}}$ ratio to match a typical urban level of $\sim 3: 1 \mathrm{ppbC} \mathrm{ppbNO}_{\mathrm{x}}^{-1}$. This helps ensure that the important radical branching channels such as the fate of organoperoxy radicals $\left(\mathrm{RO}_{2}\right)$ are similar to those in the atmosphere (Presto et al., 2005; Lim and Ziemann, 2009; $\mathrm{Ng}$ et al., 2007). However, values of other parameters were outside of typical atmospheric ranges. Mixing ratios of individual organic gases were typically less than $1 \mathrm{ppb}$, but were as high as $20 \mathrm{ppbv}$ for the highest-emitting vehicle. $\mathrm{NO}_{\mathrm{x}}$ levels were between 0.1 and 2.4 ppmv. In addition, the mix of organics inside the chamber (gasoline exhaust + propene) is different than a typical urban atmosphere. However, our goal is to understand the fraction of the emissions (yield) that form SOA, which is less sensitive to absolute concentrations, especially if the organic aerosol levels in the chamber are atmospherically relevant. Initial concentrations for select pollutants (NO, $\mathrm{NO}_{2}, \mathrm{CO}_{2}$, etc.) for all the chamber experiments are listed in Table S1 in the Supplement.

\subsection{Data analysis}

Pollutant data are reported on a fuel basis (mg-pollutant kgfuel $^{-1}$ ):

$\mathrm{EF}=[\mathrm{P}] \cdot\left(\frac{\mathrm{MW}_{\mathrm{CO}_{2}}}{\left[\Delta \mathrm{CO}_{2}\right]}+\frac{\mathrm{MW}_{\mathrm{CO}}}{[\Delta \mathrm{CO}]}+\frac{\mathrm{MW}_{\mathrm{NMOG}}}{[\Delta \mathrm{NMOG}]}\right) \cdot \frac{\mathrm{C}_{\mathrm{f}}}{\mathrm{MW}_{\mathrm{C}}}$,

where $[\mathrm{P}]$ is the background-corrected pollutant concentration in $\mu \mathrm{g} \mathrm{m}^{-3}$; $\left[\mathrm{CO}_{2}\right]$, [CO], [NMOG] are the backgroundcorrected concentrations of $\mathrm{CO}_{2}, \mathrm{CO}$ and nonmethane organic gases in the chamber in $\mu \mathrm{g} \mathrm{m}^{-3}$; and $\mathrm{MW}_{\mathrm{C}}, \mathrm{MW}_{\mathrm{CO}_{2}}$, $\mathrm{MW}_{\mathrm{CO}}$, and $\mathrm{MW}_{\mathrm{NMOG}}$ are the molecular weights of $\mathrm{C}, \mathrm{CO}_{2}$, $\mathrm{CO}$ and NMOG. $\mathrm{C}_{\mathrm{f}}$ is the measured mass fraction of carbon in the gasoline $\left(0.85 \mathrm{~kg} \mathrm{C} \mathrm{kg} \mathrm{fuel}^{-1}\right.$, Table S3 in the Supplement).

The fragmentation table from Allan et al. (2004) was used to interpret AMS data. The contribution of gas-phase $\mathrm{CO}_{2}$ to the AMS $m / z 44$ signal was corrected using the measured $\mathrm{CO}_{2}$ concentrations as a function of time. Maximum $\mathrm{CO}_{2}$ levels in the chamber after exhaust injection ranged from 515 to $890 \mathrm{ppmv}$. There was no evidence of organic particle signal at $m / z 28\left(\mathrm{CO}^{+}\right)$. The approach of Farmer et al. (2010) indicates that only a minor fraction (typically $<5 \%$ ) of the nitrate mass (which was usually quite small) was attributable to organics.

To quantify SOA production the smog chamber data were corrected for the loss of particles and vapors to the chamber walls. Details of this correction are contained in the Supplement. The loss of organic particulate mass to the walls is well constrained. It is treated as a first-order process (McMurry and Grosjean, 1985) with a rate constant determined by fitting the $\mathrm{BC}$ data measured using the Aethalometer. The wall-loss rate constant was determined separately for each experiment because it depends on the size and shape of the chamber, turbulence in the chamber and the particle size and charge distribution (Presto et al., 2005). The average particle wall-loss rate for all the experiments was $0.40 \pm 0.095 \mathrm{~h}^{-1}$ (i.e., after approximately $2.5 \mathrm{~h}$ the BC concentration decreased to $37 \%$ of its initial value). For vehicles with low $\mathrm{BC}$ emissions the rate constant was determined from the measured loss of sulfate seed particles.

Using BC (or any of the other species) as a tracer for particle wall loss assumes that it is internally mixed with the organic aerosol. This assumption was evaluated using particle size distribution data measured with the SMPS and AMS, which showed that during most experiments the SOA condensed onto the primary-mode aerosol to create an internally mixed system. However, in a few experiments significant particle mass was formed from nucleation. In these experiments it was necessary to adjust the wall-loss rate to account for the 

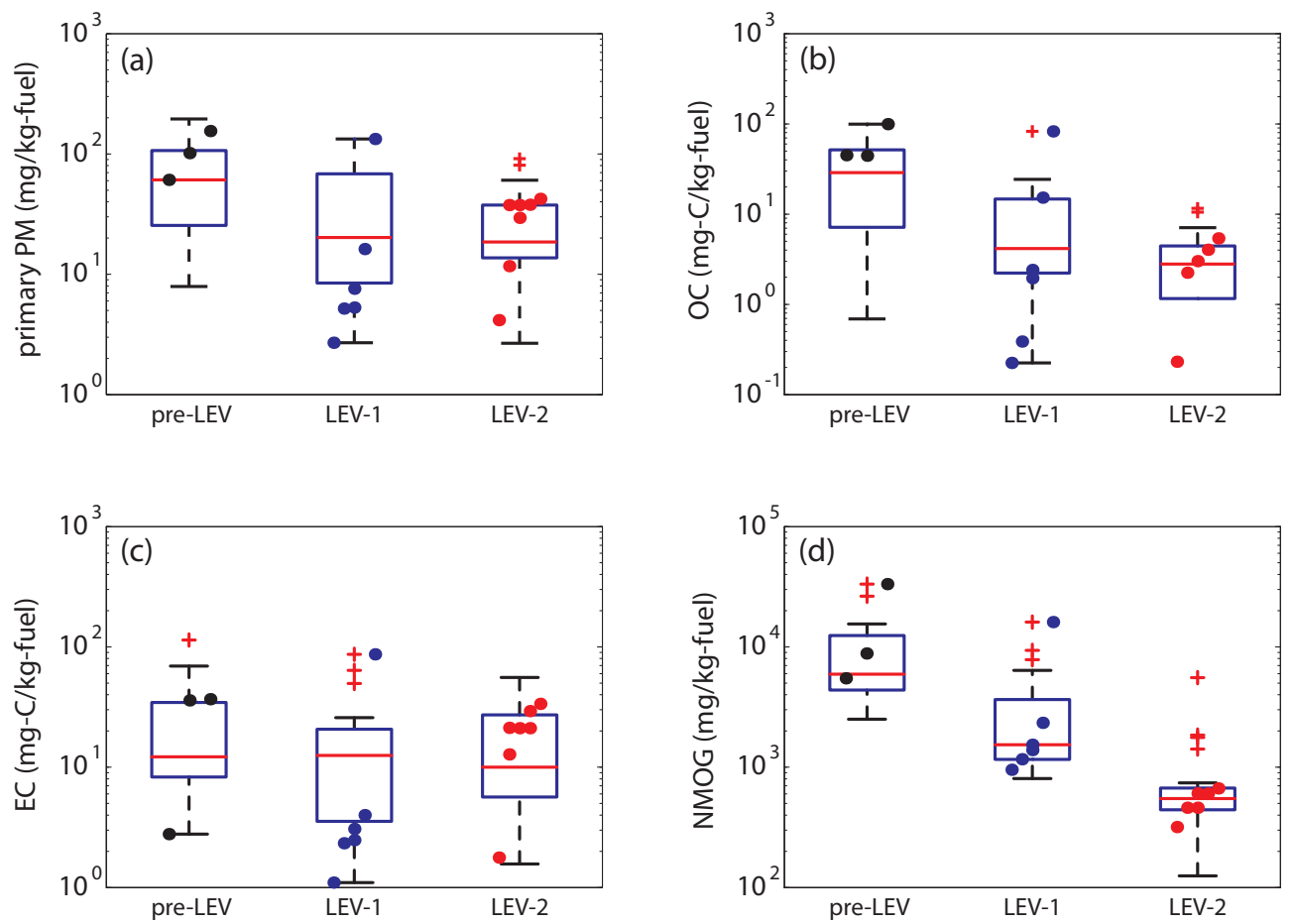

Fig. 2. Cold-start primary emissions from light-duty gasoline vehicles tested in the smog chamber shown as individual data points overlaying boxplots of the data from entire test fleet (May et al., 2014). The primary emissions are measured from the constant volume sampler (CVS): (a) total primary PM from gravimetric analysis, (b) OC and (c) EC components of primary PM from thermal-optical analysis of quartz filters and (d) nonmethane organic gases. The 15 chamber vehicles include 3 unique pre-LEV vehicles (black circles), 6 unique LEV1 vehicles (blue circles) and 6 unique LEV2 vehicles (red circles). The central marks on the boxplots are medians, the edges of the boxes are the 25 th and 75 th percentiles, the whiskers extend to the most extreme data points not considered outliers, and outliers $(>1.5 \times$ interquartile range $)$ are plotted individually with the "+" symbol.

more rapid loss of smaller nucleation mode particles. This correction is discussed in the Supplement.

The loss of condensable organic vapors to wall-bound particles is estimated for two cases (Weitkamp et al., 2007). A lower bound estimate assumes no loss of vapors to the chamber walls - essentially that the mass transfer resistance to the walls is much greater than to the suspended particles. It is equivalent to the " $\omega=0$ " correction utilized in previous studies (Weitkamp et al., 2007; Miracolo et al., 2011). The second estimate assumes that the particles lost to the walls during an experiment remain in equilibrium with the vapor phase (" $\omega=1$ " correction; Weitkamp et al., 2007); therefore, the loss of organic vapors scales with the ratio of the mass of particles on the walls to particles in suspension. The two vapor loss estimates diverge as more particle mass is lost to the chamber walls, increasing the uncertainty in the wall-loss-corrected SOA mass as an experiment progresses (Hildebrandt et al., 2009). With one vehicle (experiments pre-LEV3.2 and pre-LEV3.3) we imposed a $5: 1$ upper bound on the ratio of OA on the wall to suspended OA. In our judgment $\mathrm{OA}$ estimates beyond this ratio become too uncertain; therefore, we assumed that these two experiments were complete when this ratio was reached. If we had cho- sen a higher limit (or no limit), our estimate of the SOA production from this vehicle would have been greater, but this would not change any of the conclusions of the paper. We do not consider the loss of organic vapors directly to the chamber walls (in distinction to their loss to wall-bound particles) (Matsunaga and Ziemann, 2010). This is highly uncertain; if included, it would increase our estimated SOA production.

\section{Results}

Figure 2 presents primary emissions data measured from the CVS, including gravimetric PM mass, organic carbon, elemental carbon, and NMOG. Data for the 15 vehicles used for the smog chamber experiments are indicated by the filled circles. The chamber vehicles shown in Fig. 2 are a subset of a larger test fleet of 63 LDGVs (May et al., 2014). To evaluate the representativeness of the emissions from smog chamber vehicles, box-whisker plots of the data from the entire vehicle fleet are shown overlaying the individual data points for the smog chamber experiments in Fig. 2.

Despite some vehicle-to-vehicle variability, Fig. 2 indicates that for most pollutants there is a clear reduction in emissions from newer, lower-mileage vehicles that met more 
stringent emission standards relative to older vehicles. For example, the NMOG emissions from the median LEV2 vehicle are about an order of magnitude lower than the emissions from the median pre-LEV vehicle. However, emissions of some pollutants do not exhibit a downward trend with model year grouping; for example, there is no statistically significant trend $(p=0.389)$ in the EC emissions. The lack of a trend in the EC emissions with vehicle age is not surprising. LEV1 gasoline vehicles already met the LEV2 PM emissions standard; therefore, changes to engine control/aftertreatment from LEV1 to LEV2 were not aimed at reducing nonvolatile EC particles or primary PM more broadly, and this fact is reflected in the relatively constant EC value shown in Fig. 2 across the LEV classes.

Figure 2 demonstrates that emissions from the vehicles used for smog chamber experiments are reasonably representative of the larger test fleet. From the perspective of SOA formation, the NMOG emissions are presumably the most important metric. The NMOG emissions from most of the smog chamber vehicles cluster around the median vehicle for a given model year range. There was more variability in the primary PM emissions; for example, two of the LEV1 chamber vehicles (LEV1-1 and LEV1-6) had the highest and lowest emissions for the entire set of LEV1 vehicles. There were also some systematic differences in the EC emissions from the chamber vehicles relative to the overall vehicle fleet. The EC emissions from the LEV1 chamber vehicles were systematically lower than the overall LEV1 fleet, while the EC emissions from the LEV2 chamber vehicles were systematically higher than the overall LEV2 fleet.

An important objective of this work was to quantify the SOA formation. To better understand the SOA precursor emissions, comprehensive speciation was performed on the volatile organic compound emissions. Figure 3 presents the median data for each vehicle class, which are representative of the larger fleet. Instead of presenting results for individual compounds, the speciation results are classified into three categories: speciated SOA precursors, speciated non-SOA precursors, and unspeciated NMOG. The mapping of individual compounds to these categories is summarized in Table S5 in the Supplement. Briefly, speciated SOA precursors include single-ring aromatics $\left(\mathrm{C}_{6}\right.$ to $\left.\mathrm{C}_{12}\right)$ and mid-weight VOCs $\left(\mathrm{C}_{9}\right.$ to $\left.\mathrm{C}_{12}\right)$. The higher-molecular-weight compounds $\left(\mathrm{C}_{9}\right.$ and larger) are less volatile than the lighter $\left(\mathrm{C}_{8}\right.$ and smaller) compounds, and are, therefore, more likely to condense into the solid or liquid phase as a result of photooxidation. Speciated non-SOA precursors include all of the other speciated compounds. The unspeciated mass is the difference between the total NMOG emissions and the sum of the speciated compounds. Figure 3 indicates that $\sim 70 \%$ of the mass of the NMOG emissions from the LEV1 and LEV2 vehicles was speciated. This level of mass closure is similar to or slightly better than that of Schauer et al. (1999, 2002).

The absolute emissions of speciated SOA precursors, speciated non-SOA precursors and unspeciated NMOGs are

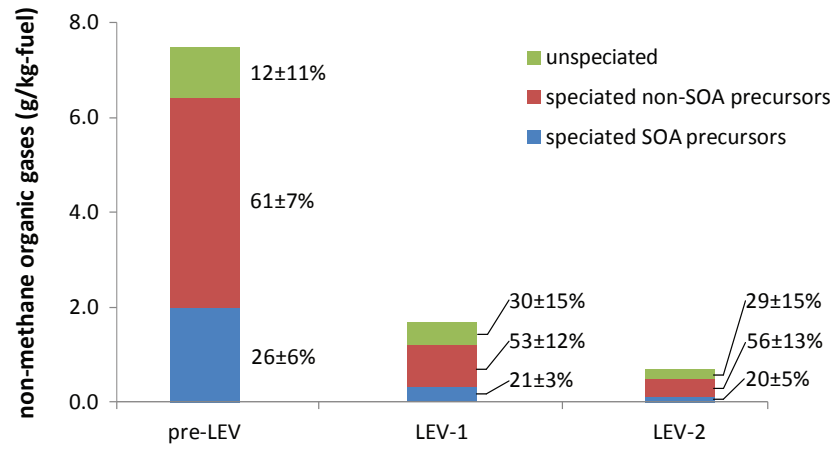

Fig. 3. Median nonmethane organic gas (NMOG) emissions for each class of light-duty gasoline vehicles. The emissions have been lumped into three broad categories: (1) "speciated SOA precursors," including single-ring aromatics $\left(\mathrm{C}_{6}\right.$ to $\left.\mathrm{C}_{12}\right)$, mid-weight VOCs $\left(\mathrm{C}_{9}\right.$ to $\mathrm{C}_{12}$ ); (2) all other speciated compounds ("speciated non-SOA precursors"); and (3) "unspeciated" compounds, defined as the difference between the total NMOG and the speciated emissions. The bars represent the median absolute values; the values next to the bars represent the median $( \pm 1 \sigma)$ fractional contribution of each emission category (i.e., precursor, nonprecursor, unspeciated) to the total NMOG for each vehicle class.

lower from newer vehicles. In addition, the relative amount of speciated SOA precursors has remained approximately constant as a function of LEV class at about $20-26 \%$ of the NMOG mass. Therefore, despite large vehicle-to-vehicle differences in the absolute magnitude of the NMOG emissions, vehicle-to-vehicle differences in the relative amounts of speciated emissions were modest. However, on average, a larger fraction of the NMOG emissions from the newer (LEV1 and LEV2) vehicles could not be speciated $(\sim 30 \%$ on a mass basis) compared to the older (pre-LEV) vehicles $(\sim 12 \%)$.

The primary emissions data alone provide a preliminary estimate of the relative importance of primary PM emissions versus SOA formation. Combining the data in Figs. $2 \mathrm{~d}$ and 3 indicates that emissions of speciated SOA precursors are about 50 times higher than the POA emissions for all preLEV and LEV1 categories and about 30 times higher for LEV2 vehicles (assuming the ratio of organic mass to organic carbon is 1.4; Lipsky and Robinson, 2006). Yields for aromatics and large $n$-alkanes are around $10 \%$ for typical atmospheric conditions (Hildebrandt et al., 2009; $\mathrm{Ng}$ et al., 2007; Presto et al., 2010; Tkacik et al., 2012). Therefore, the emissions data themselves indicate that the SOA formed from vehicle emissions will likely exceed the POA. This conclusion becomes even stronger if the unspeciated emissions also form SOA and one accounts for sampling artifacts and partitioning biases in the quartz filter POA data plotted in Fig. 2b (May et al., 2013b). The smog chamber experiments provide a direct test of this hypothesis. 

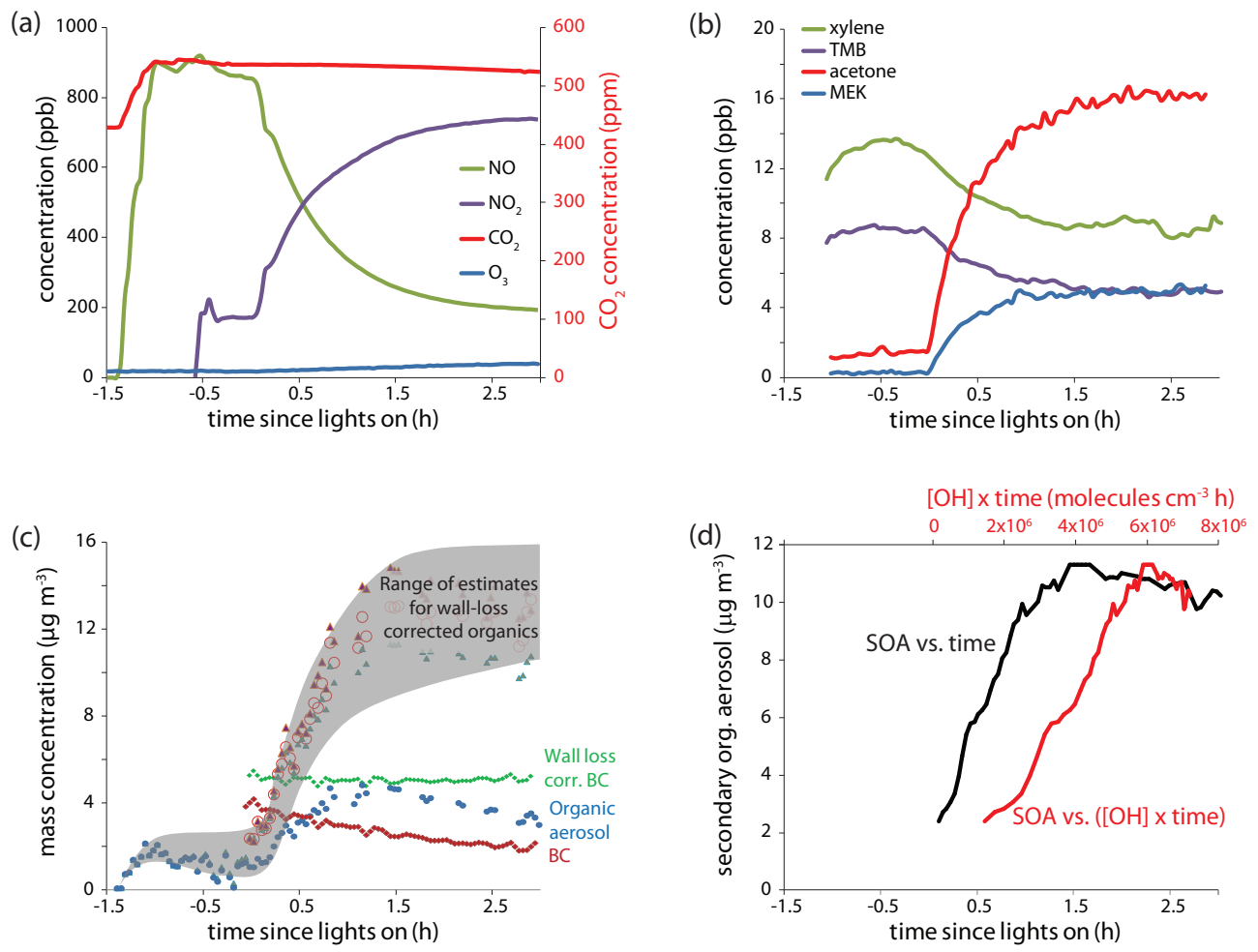

Fig. 4. Measured gas and particle evolution during a typical smog chamber experiment (LEV1-6.2 experiment): (a) $\mathrm{NO}_{\mathrm{x}}, \mathrm{O}_{3}$ and $\mathrm{CO}_{2}$; (b) selected primary (xylene and trimethylbenzene, TMB) and secondary (acetone and methyl ethyl ketone, MEK) organic gases; (c) measured and wall-loss-corrected black carbon (BC) and organic aerosol concentrations; and (d) wall-loss-corrected SOA production (average of two correction methods) as a function of time (black, lower $x$ axis) and $\mathrm{OH}$ exposure (red, upper $x$ axis). Within the range of $-1.5 \mathrm{~h}<$ time $<-1.0 \mathrm{~h}$, the chamber was filled with diluted emissions from the vehicle; for $-1.0 \mathrm{~h}<$ time $<0 \mathrm{~h}$, the primary PM was characterized; at time $>0 \mathrm{~h}$ the UV lights were on and photooxidation generated SOA. The grey shaded area in (c) indicates the range of wall-loss correction estimates discussed in the text. A four-period moving average is used to smooth both data sets in (d).

\subsection{Secondary organic aerosol formation}

Figure 4 plots the temporal evolution of both particle- and gas-phase species measured during a typical cold-start smog chamber experiment. First, vehicle emissions were added to the chamber throughout the entire UC test, increasing the pollutant concentrations inside the chamber. The UC cycle was completed and engine shut off at time $=-1.0 \mathrm{~h}$. HONO was added to the chamber at approximately time $=-0.5 \mathrm{~h}$, modestly increasing $\mathrm{NO}_{2}$ concentrations. Propene was also added at this time to adjust the $\mathrm{VOC} / \mathrm{NO}_{\mathrm{x}}$ ratio to about $3: 1 \mathrm{ppbC} \mathrm{ppbNO}_{\mathrm{x}}^{-1}$. The loss of POA to the walls of the chamber is evident from the decay of the organic signal measured with the AMS (blue points in Fig. 4c) occurring between the time when the engine is turned off and before the lights are turned on (time $=0 \mathrm{~h}$ ).

After the UV lights were turned on, the measured organic aerosol concentrations increased for about an hour and a half, indicating substantial SOA formation. In contrast, the measured concentration of nonreactive $\mathrm{BC}$ decreased. (Due to interference during the $\mathrm{HONO}$ addition, $\mathrm{BC}$ measurements before lights were turned on are not shown; the wall-loss cor- rection was extrapolated back in time to when the emissions were first injected.) The grey shaded region in Fig. 4c shows the range of wall-loss correction estimates, which become more uncertain as the experiment progresses and more particle mass is lost to the chamber walls (Hildebrandt et al., 2009). After $3 \mathrm{~h}$ of photooxidation the wall-loss-corrected organic aerosol concentration increased by roughly a factor of 6 from $\sim 2 \mu \mathrm{g} \mathrm{m}^{-3}$ at the beginning of the experiment to $\sim 12 \mu \mathrm{g} \mathrm{m}^{-3}$ at the end. During the $3 \mathrm{~h}$ of UV irradiation much of the NO and primary hydrocarbons are oxidized to $\mathrm{NO}_{2}$ and more oxygenated organics, respectively (Fig. 4a, b).

In a few experiments there was significant inorganic nitrate formation (comparable to the SOA mass). This requires ammonia to neutralize the nitric acid formed from the oxidation of $\mathrm{NO}_{\mathrm{x}}$. We hypothesize that organic nitrate formed in experiments with vehicles that emitted significant amounts of ammonia, but the ammonia concentrations in the chamber were not measured.

Hydroxyl radical $(\mathrm{OH})$ levels in the chamber were inferred from the decay of individual VOCs (e.g., deuterated butanol, toluene, xylenes, trimethylbenzene and propene) measured 

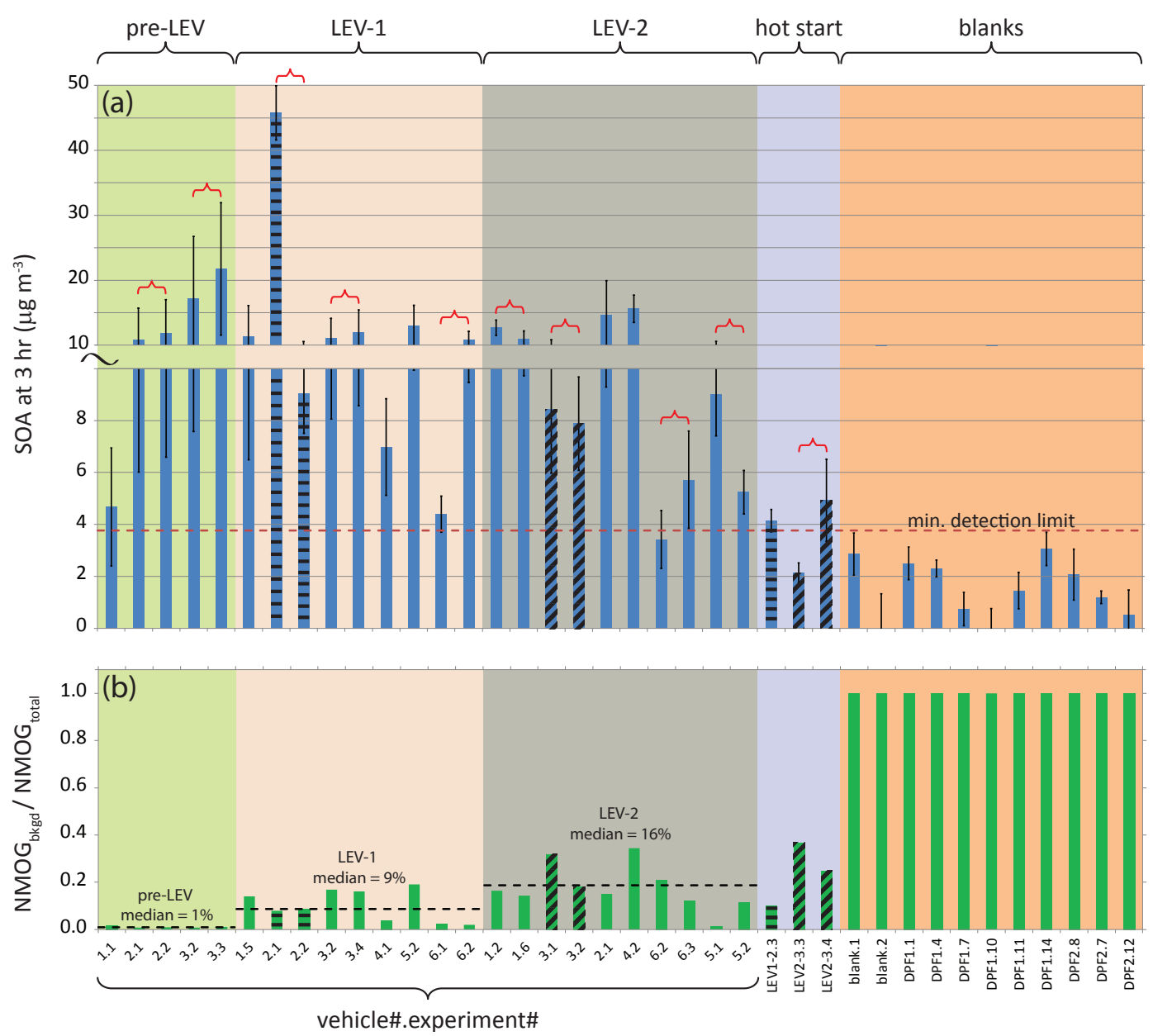

Fig. 5. (a) Measured wall-loss-corrected SOA concentration (assuming no blank correction) after 3 h of photooxidation and (b) fractional contribution of background NMOG to smog chamber. Blue bars in (a) show the average SOA based on the two different wall-loss correction methods, and the range of these estimates is shown by the error bars. The red braces in (a) indicate duplicate experiments. Hot-start and normal UC driving cycle experiments with two vehicles (LEV1-2 and LEV2-3) are denoted by the horizontal and diagonal black lines inside of the bars, respectively. (SOA from the pre-LEV hot-start experiment was not measured due to instrument failure.) The horizontal dashed red line in (a) indicates the minimum SOA detectible by the instruments. "Blanks" included two dynamic blanks and nine experiments with diesel-particulate-filter-equipped heavy-duty diesel trucks (Gordon et al., 2013a). The dashed black lines in (b) indicate the median values of $\mathrm{NMOG}_{\mathrm{bkgd}} / \mathrm{NMOG}_{\mathrm{total}}$ for the three LEV classes.

with the PTR-MS (Atkinson and Arey, 2003). OH exposures (OH multiplied by time) were calculated based on the loss of VOCs via reaction with $\mathrm{OH}$ as described by the rate law

$\frac{d}{d t}[\mathrm{VOC}]=-k[\mathrm{OH}][\mathrm{VOC}]$.

After integrating from $t_{0}$ to $t, \mathrm{OH}$ exposure is given by

$[\mathrm{OH}] \cdot t=-\frac{1}{k} \ln \left(\frac{[\mathrm{VOC}]_{t}}{[\mathrm{VOC}]_{0}}\right)$.

We calculated the $\mathrm{OH}$ exposure according to the equation above using concentrations of three to six different VOCs (toluene, benzene, xylenes, trimethylbenzene, propene and butanol) measured with a PTR-MS. The different estimates were then fit to derive the $\mathrm{OH}$ exposure.
Average $\mathrm{OH}$ levels during photooxidation were roughly $5 \times 10^{6}$ molecules $\mathrm{cm}^{-3}$, which is representative of summer daytime atmospheric concentrations (Seinfeld and Pandis, 1998). The trends in Fig. 4b indicate that $\mathrm{OH}$ levels were much higher during the initial stages of the photooxidation phase of the experiment and then fell as the HONO was consumed by photolysis. Table S1 in the Supplement summarizes the $\mathrm{OH}$ data for all of the experiments.

Figure $4 \mathrm{c}$ shows that the wall-loss-corrected organic aerosol concentrations level off at a constant value as the experiment progresses, potentially indicating that SOA formation was complete. However, the xylene and trimethylbenzene concentrations also stopped decaying after $\sim 1.5-$ $2 \mathrm{~h}$, which suggests that the slowing of the SOA production is probably due to decreased oxidant concentrations, rather 
than exhaustion of the SOA precursors. Figure $4 \mathrm{~d}$ presents the SOA data as a function of $\mathrm{OH}$ exposure (i.e., $[\mathrm{OH}]$ multiplied by the exposure time) and as a function of time. The SOA production increased linearly with $\mathrm{OH}$ exposure, indicating that the SOA formation was not completed after $3 \mathrm{~h}$ of photooxidation.

Summer daytime $\mathrm{OH}$ concentrations are typically in the range of $5-10 \times 10^{6}$ molecules $\mathrm{cm}^{-3}$ (Seinfeld and Pandis, 1998); therefore, these experiments correspond to approximately $1.5-3 \mathrm{~h}$ of atmospheric aging under typical summertime conditions. Measurements made downwind of urban areas suggest that SOA production continues for about $48 \mathrm{~h}$ at an $\mathrm{OH}$ concentration of $3 \times 10^{6}$ molecules $\mathrm{cm}^{-3}$ (de Gouw et al., 2005). If this is true for LDGV exhaust, then our chamber experiments might substantially underestimate the ultimate SOA formation potential of LDGV emissions.

Figure 5 compiles the wall-loss-corrected SOA concentrations measured at the end of each experiment (after $3 \mathrm{~h}$ of photooxidation). Data are shown for 24 cold-start LDGV experiments, 3 hot-start LDGV experiments, 2 chamber blank experiments, and 9 hot-start experiments performed with catalyzed diesel particulate filter (DPF)-equipped heavy-duty diesel vehicles (Gordon et al., 2013a). The chamber blank and hot-start DPF-equipped vehicle data quantify the potential contribution of contamination to the measured SOA formation. A chamber blank followed the same procedures as an actual vehicle test except that the chamber was filled with CVS dilution air only (no vehicle emissions) for the same period of time as the UC. HONO, propene, deuterated butanol and ammonium sulfate seed particles were then added to the chamber and the UV lights were turned on for $3 \mathrm{~h}$. The decay of butanol and propene were monitored with the PTR-MS to verify similar amounts of oxidation $(\mathrm{OH}$ exposure) to those in experiments with vehicle exhaust. The DPFequipped vehicle experiments followed the same procedure as LDGV and chamber blank tests (Gordon et al., 2013a). Both primary particle and NMOG emissions from the hotstart DPF-equipped vehicle experiments were extremely low, often below ambient levels (Gordon et al., 2013a).

The average wall-loss-corrected SOA mass (assuming no blank correction) for all the cold-start UC chamber experiments plotted in Fig. 5a is $12 \pm 8.4 \mu \mathrm{g} \mathrm{m}^{-3}$, which is within the range of typical urban PM concentrations. Therefore the gas-particle partitioning inside the chamber should be representative of the urban atmosphere. The average wall-losscorrected SOA concentration for the hot-start experiments was much lower, $3.7 \pm 1.4 \mu \mathrm{g} \mathrm{m}^{-3}$. Only $1.4 \pm 1.2 \mu \mathrm{g} \mathrm{m}^{-3}$ of wall-loss-corrected SOA formed during blank or DPFequipped vehicle experiments. Therefore the blank corresponded to $12 \%$ of the SOA formed in the average cold-start UC experiment, but a much larger fraction of the SOA in the hot-start experiments. We defined the minimum detection limit (MDL) as 3 times the standard deviation of the SOA measured in the two blank and nine hot-start DPF-equipped vehicle experiments. The end-of-experiment MDL for SOA was $3.8 \mu \mathrm{g} \mathrm{m}^{-3}$ (dashed red line in Fig. 5a). All but two of the LDGV experiments lie above the MDL; therefore, the trends in Fig. 5 are due to the addition of dilute LDGV exhaust to the chamber, and they are not primarily a result of SOA produced from the photooxidation of background gasphase components.

The SOA measured during blank experiments presumably forms from background organic gases in the CVS dilution air (HEPA-filtered ambient air) and/or organic vapors that desorb from the CVS, transfer line and/or chamber walls. Figure $5 \mathrm{~b}$ plots the estimated fractional contribution of the background organic gases to the chamber based on measurements made at the inlet and exit of the CVS tunnel. During the blank and DPF-equipped experiments, the CVS-dilution air contributed essentially the entire NMOG burden in the chamber. In contrast, during the median pre-LEV, LEV1 and LEV2 experiments, organics in the CVS dilution air typically contributed 1,9 and $16 \%$ (on a mass basis), respectively, of the total NMOG burden. Therefore, the vast majority of the organic gases inside the chamber during all of the cold-start LDGV experiments were vehicle emissions.

One issue that the blank experiments do not address is the possible contribution of heat-released contamination. For example, the heat release of hydrocarbons adsorbed from the walls of the transfer tube used to conduct exhaust from the vehicle to the CVS tunnel has been shown to cause nucleation (Maricq et al., 1999). The potential contribution of this mechanism to the SOA precursor burden in the smog chamber is not known. However, Fig. 5 indicates that heat-release contamination was not a significant source of SOA precursors for the DPF-equipped vehicle experiments (although these experiments were conducted in a different facility than the LDGV experiments).

Figure 5 also compares results from 10 sets of duplicate chamber experiments - 2 different pre-LEV, 3 LEV1, 4 LEV2 and 1 set of duplicate LEV2 hot-start experiments. There is good agreement $( \pm 25 \%$ of the average of each duplicate pair) in SOA production for 7 of the 10 pairs of duplicate experiments. SOA production for the LEV1-6.1 and LEV1-6.2 experiments differed substantially. This was primarily due to high experiment-to-experiment variability in the emissions from the LEV1-6 vehicle, not measurement uncertainty. LEV1-6 had a malfunctioning oxygen sensor, which resulted in highly variable and high emissions (see Table S1 in the Supplement). This vehicle was the upper outlier in Fig. 2. The reason for the very large difference in SOA produced during duplicate experiments with LEV1-2 and LEV25 is not known. There was poor agreement between the two duplicate hot-start experiments with LEV2-3 $( \pm 56 \%$ of the average of the duplicates), but this may be due to the low levels of SOA production. Duplicate cold-start experiments with this vehicle (which produced nearly an order of magnitude more SOA) agreed to within $1 \%$. 

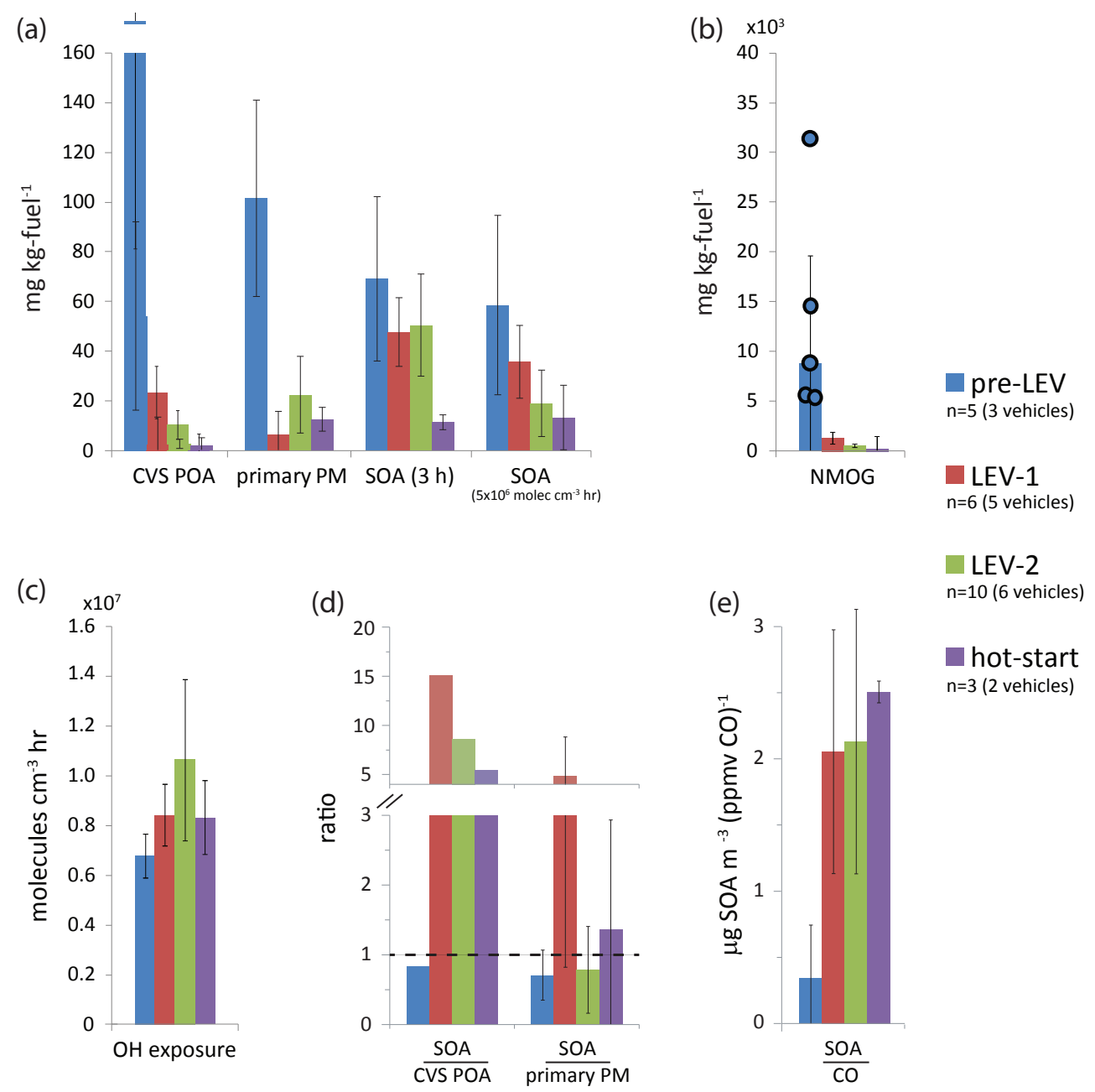

Fig. 6. Primary emissions and chamber data for hot- and cold-start UC chamber experiments with vehicles from the three LEV classes. (a) Median POA, primary PM (primary PM was not measured for LEV2-3.1), and (b) NMOG emissions measured in the CVS (filled circles represent individual measurements). Median SOA production (a) during 21 cold-start UC chamber experiments after $3 \mathrm{~h}$ of photooxidation ("SOA ( $3 \mathrm{~h}$ )") and after $5 \times 10^{6}$ molecules $\mathrm{cm}^{-3} \mathrm{~h}$ of OH exposure (LEV1-2.1 and high-emitter (LEV1-6) outliers were removed). (c) Median $\mathrm{OH}$ exposures after $3 \mathrm{~h}$ of photooxidation. (d) Median ratios of SOA to primary PM and SOA to POA after $5 \times 10^{6} \mathrm{molecules} \mathrm{cm}^{-3} \mathrm{~h}$ of $\mathrm{OH}$ exposure. The dashed horizontal line in (d) represents $1: 1$. (e) Median ratios of SOA $\left(5 \times 10^{6} \mathrm{molecules} \mathrm{cm}^{-3} \mathrm{~h}\right.$ of OH exposure $)$ to $\mathrm{CO}$. Error bars represent uncertainty/variability propagated through all measured variables. Only one experiment is shown (no error bar) for the hot-start SOA-to-POA ratio. Error bars for other SOA-to-POA ratios are not included; they are large due to several experiments with extremely low POA emissions.

\subsection{Effects of vehicle age and hot and cold start on SOA formation}

Important objectives of the test plan were to investigate the influence of driving cycle (hot versus cold start) and vehicle age on SOA formation and to quantify the relative importance of SOA formation to primary PM emissions. In order to make consistent comparisons across the entire set of experiments, Fig. 6 presents the SOA data on a mass-offuel-burned basis and as ratios of SOA to primary PM mass, SOA to POA and SOA to CO for comparison with ambient OA measurements. (One cannot simply compare the endof-experiment SOA concentration data in Fig. 5 because of experiment-to-experiment differences in dilution.) Figure 6 presents data for the median cold-start experiment for each vehicle class (pre-LEV, LEV1, LEV2) and for the median hot-start experiment. The trends in the median data reflect those of the entire test fleet. The SOA data were measured at (1) the end of the experiment ("SOA ( $3 \mathrm{~h})$ ", after $3 \mathrm{~h}$ of photooxidation) and (2) after $5 \times 10^{6}$ molecules $\mathrm{cm}^{-3} \mathrm{~h}$ of $\mathrm{OH}$ exposure ("SOA"). (Figure 6d, e use the SOA measurements taken after $5 \times 10^{6}$ molecules $\mathrm{cm}^{-3} \mathrm{~h}$ of $\mathrm{OH}$ exposure.) The primary emissions (CVS POA and primary PM) data were measured in the CVS. The SOA data in Fig. 6 have been corrected for the average end-of-experiment SOA formation 
measured in the two blank and nine DPF-equipped vehicle experiments. (Figure 5a plots the measured SOA concentrations without any blank SOA correction.)

Figure 6a indicates that the median SOA mass (per mass of fuel burned) formed during the median hot-start experiment was only 22,37 and $70 \%$ of that formed during median cold-start pre-LEV, LEV1 and LEV2 experiments (after $5 \times 10^{6}$ molecules $\mathrm{cm}^{-3} \mathrm{~h}$ of $\mathrm{OH}$ exposure), respectively. It is well known that significant emissions occur during cold start before the catalyst has become active. For example, the hot-start NMOG emissions for vehicle LEV1-2 were a factor of 7 lower than the cold-start emissions for this vehicle. However, this reduction in NMOG emissions was larger than the reduction in SOA formation (hot-start SOA was only a factor of 2 lower than cold-start SOA), underscoring the fact that there is not a one-to-one relationship between these parameters. This is not surprising since SOA precursors comprise only a subset of the NMOG emissions (Fig. 3). The data suggest that catalyst warm-up is an important factor in controlling the emissions of SOA precursors. Nordin et al. (2013) and Platt et al. (2013) also report substantial SOA formation from dilute cold-start LDGV emissions.

Figure 6 also shows that the median SOA production $(\mathrm{mg}$ $\mathrm{kg}$-fuel ${ }^{-1}$ ) measured during the cold-start LEV2 experiments was only a factor of 3 less than that measured during the median pre-LEV experiment. Some reduction in SOA formation was expected given the large differences in NMOG emissions. However, the reduction in SOA formation was much less than the factor of 11 to 15 (based on median of entire test fleet and median of smog chamber experiments, respectively) difference in the NMOG emissions between these two vehicle classes (Fig. 3 shows medians of the larger test fleet of 63 LDGVs from May et al. 2014), highlighting once again the complex relationship between NMOG emissions and SOA formation. The fact that relatively little SOA was formed in the chamber blank, DPF-equipped vehicle, and hot-start experiments (Fig. 5) indicates that the unexpected similarity in the SOA formation measured across the set of cold-start experiments was not simply due to contamination.

SOA production also depends on oxidant exposure and gas-particle partitioning. We investigated whether these mechanisms influenced the conclusions about the trends in SOA formation. Increased oxidant exposure will generally lead to more SOA production (Lambe et al., 2012). Vehicle emissions are mainly comprised of saturated species, so $\mathrm{OH}$ is the most important oxidant. Figure $6 \mathrm{c}$ plots the median $\mathrm{OH}$ exposure for the sets of chamber experiments (pre-LEV, LEV1, LEV2, hot start). The $\mathrm{OH}$ exposures for the hot- and cold-start experiments were similar (Table S1 in the Supplement). However, $\mathrm{OH}$ exposures were about $60 \%$ higher during experiments with new, lower-emitting (LEV1 and LEV2) vehicles than during pre-LEV experiments (Table $\mathrm{S} 1$ in the Supplement). This was due to differences in VOC levels in the chamber - higher VOC emissions reduced $\mathrm{OH}$ levels in the pre-LEV experiments. Therefore, while the greater $\mathrm{OH}$ exposure in the LEV1 and LEV2 experiments leads to enhanced SOA formation, it would need to be a factor of 5 higher (not just $60 \%$ ) to explain the similarity in the SOA formation across the different classes of vehicles. This is quantitatively demonstrated by the effective yield analysis presented later in the manuscript. Therefore, the similarity in SOA production across the set of LDGV tests was not due to differences in $\mathrm{OH}$ exposure.

SOA production is influenced by gas-particle partitioning (Odum et al., 1996). Higher aerosol concentrations cause a larger fraction of the semivolatile organics to partition into the condensed phase. However, this phenomenon does not explain the similarity in the measured SOA production for the different vehicle classes. The organic aerosol concentrations inside the chamber were lower during the experiments with the newer, lower-emitting vehicles (LEV1 and LEV2) than the older, higher-emitting vehicles (pre-LEV). This should increase (not decrease) the differences between the LEV2 and pre-LEV results; therefore, gas-particle partitioning does not explain the discrepancy between NMOG emissions and the SOA production. Furthermore, the POA reduction between hot- and cold-start experiments with LEV1 and LEV2 vehicles was relatively small ( $\sim 25 \%$ for LEV1 and $\sim 20 \%$ for LEV2); therefore, gas-particle partitioning alone cannot explain the large SOA reduction observed during the hot-start experiments either.

To quantify the importance of SOA formation relative to the primary PM emissions, Fig. 6d presents the ratios of the end-of-experiment, wall-loss-corrected SOA measured in the smog chamber to both POA and gravimetric PM mass measured in the CVS. After $5 \times 10^{6}$ molecules $\mathrm{cm}^{-3} \mathrm{~h}$ of $\mathrm{OH} \mathrm{ex}-$ posure the PM concentrations inside the chamber during the cold-start LEV1 experiments were dominated by SOA (median SOA / POA ratio of 15; median SOA/ primary PM ratio of 5), and the LEV2 SOA/POA ratio was about 8. For the pre-LEV vehicles, the cold-start end-of-experiment SOA levels were similar to the primary PM and POA emissions measured in the CVS. Figure 6d indicates that SOA was approximately equal to primary PM for hot-start experiments. SOA was about a factor of 3 greater than POA for the LEV1-2.3 hot-start experiment. In essentially every experiment, SOA was either comparable to or larger than primary PM (or POA) after equal $\mathrm{OH}$ exposure. After $3 \mathrm{~h}$ of photooxidation SOA was the dominant component of the PM in the chamber. The relative contribution of SOA would likely continue to increase with further oxidation (de Gouw et al., 2005).

The ratios plotted in Fig. 6d are relative to primary PM and POA measured in the CVS. This is a useful comparison since CVS data are widely used in emissions inventories and models. However, gas-particle partitioning experiments conducted as part of this project indicate that the primary PM emissions measured in the CVS are biased high relative to the more dilute atmosphere (May et al., 2013b). The particle concentrations in the CVS were almost always much higher (a factor of 10 or more) than the ambient, biasing the 


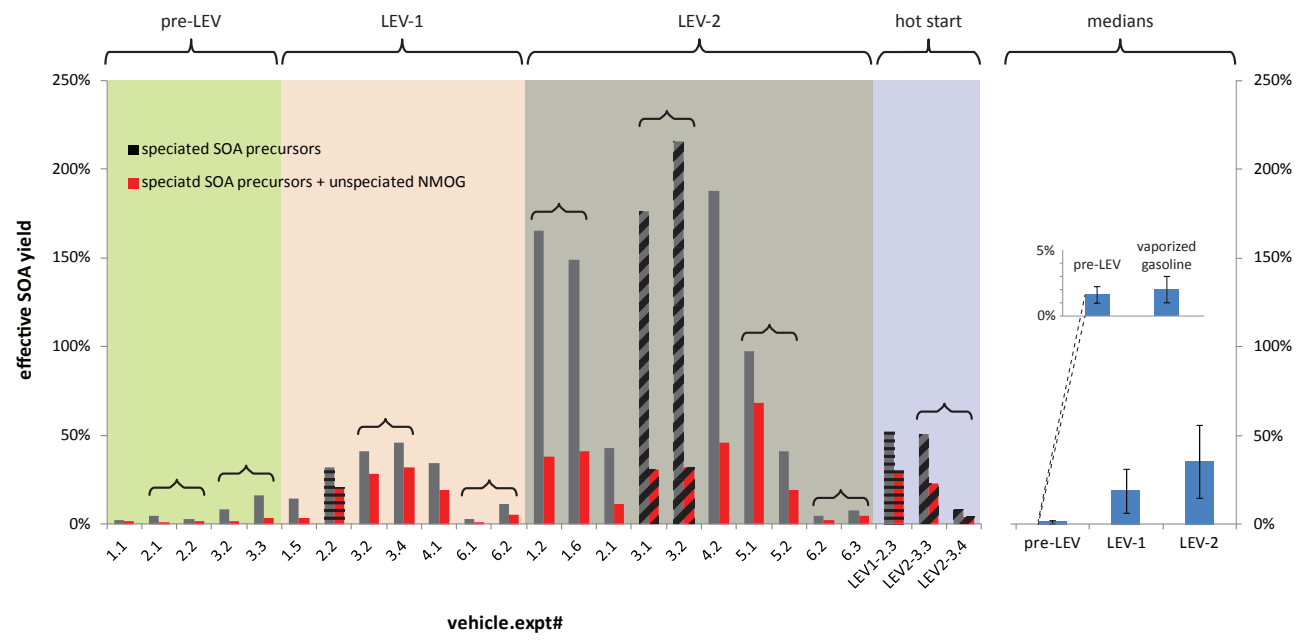

Fig. 7. Two different effective SOA yield estimates (after $3 \mathrm{~h}$ of photooxidation) for pre-LEV, LEV1 and LEV2 light-duty gasoline vehicles $(n=25)$. The grey bars represent yields assuming only traditional (speciated) SOA precursors; the red bars also include unspeciated NMOG in the effective yield calculations. The braces indicate nine sets of duplicate experiments. Hot-start and normal UC driving cycle experiments were performed with two vehicles (LEV1-2 and LEV2-3), denoted by the horizontal and diagonal black lines inside of the bars, respectively. Median $( \pm 1 \sigma)$ effective SOA yields for the three LEV classes are shown on the right side. The inset compares the SOA yield for vaporized gasoline (error bar represents the range of values measured for $1 \mu \mathrm{g} \mathrm{m}^{-3}<\mathrm{C}_{\mathrm{oa}}<10 \mu \mathrm{g} \mathrm{m}^{-3}$ ) from Jathar et al. (2013) with the yield from the pre-LEV emissions. Multiple experiments with the same vehicle were averaged before medians were calculated.

gas-particle partitioning of semivolatile organics towards the particle phase. The amount of partitioning bias varies from vehicle to vehicle depending on emission rate and CVS flow, but accounting for it would, on average, increase the ratios plotted in Fig. 6d by a factor of 2 or more.

The median ratios of SOA to $\mathrm{CO}$ are plotted in Fig. 6d. This metric is commonly used to evaluate atmospheric SOA production (de Gouw et al., 2005). For the vehicles tested here, the SOA to CO ratios are less than that measured in the atmosphere at a comparable $\mathrm{OH}$ exposure.

\subsection{Effective SOA yields and SOA mass closure}

Since the exhaust gas concentrations in the chamber were higher than typical atmospheric levels, the absolute mass concentration of SOA formed in the chamber plotted in Fig. 5 cannot be directly translated to the atmosphere. Therefore, we calculated an effective SOA yield, which quantifies the percentage of the organic emissions that must be converted to SOA in order to explain the chamber data.

$Y=\frac{M_{\mathrm{SOA}}}{\sum M_{\mathrm{VOC}_{\text {reacted }}}}=\frac{\mathrm{M}_{\mathrm{SOA}}}{\sum\left(M_{\mathrm{VOC}_{i}}\right) \cdot\left(1-\exp \left(-k_{i}[\mathrm{OH}] t\right)\right)}$,

where $Y$ is the effective SOA yield, $M_{\mathrm{SOA}}$ is the mass of SOA produced, $t$ is photooxidation time, $M_{\mathrm{VOC} i}$ and $k_{i}$ are the mass at time $t$ and $\mathrm{OH}$ reaction rate of the $i$ th VOC, and $[\mathrm{OH}]$ is the $\mathrm{OH}$ radical concentration. A SOA yield is the ratio of the measured SOA mass to the mass of reacted organic precursors; it is a standard measure of SOA production in smog chambers (Odum et al., 1996; Donahue et al., 2006). We use the term "effective" yield because LDGV exhaust is comprised of a complex mix of species; only a subset of these species was quantifiable by GC analysis. Therefore, we can only estimate the mass of reacted organic precursors. Effective SOA yields were based on SOA measured after $3 \mathrm{~h}$ of photooxidation; since $\mathrm{OH}$ exposure is intrinsic to the yield calculation, variation in SOA production due to differing $\mathrm{OH}$ exposure between experiments is accounted for.

Figure 7 plots two different effective yield estimates, each based on different components of the NMOG emissions. First we calculated an effective SOA yield accounting for the speciated compounds that are known SOA precursors ("speciated SOA precursors"). This analysis considered 75 compounds (see Table S5 in the Supplement), including singlering aromatics $\left(\mathrm{C}_{6}\right.$ to $\left.\mathrm{C}_{12}\right)$ and mid-weight VOCs $\left(\mathrm{C}_{9}\right.$ to $\mathrm{C}_{12}$ ). In sum these compounds contribute about $20 \%$ of the total NMOG emissions for the newer vehicles (LEV1 and LEV2) (Fig. 3). These compounds are commonly included in SOA models (Heald et al., 2005; Hennigan et al., 2011; Miracolo et al., 2010, 2011; Vutukuru et al., 2006). The reacted mass of each precursor was calculated from its initial concentration (inferred from the CVS measurements), the $\mathrm{OH}$ exposure in the chamber and published reaction rate constants for each species with OH (see Table S5 in the Supplement).

Figure 7 indicates that for the pre-LEV vehicles the effective yield for speciated precursors was $2-12 \%$ (depending on experiment). In other words, $2-12 \%$ of the mass of reacted speciated SOA precursors listed in Table S5 in the Supplement must form SOA to explain pre-LEV smog chamber data. This is comparable to published yields for singlering aromatics, $n$-alkanes, and other SOA precursors found 
in vehicle exhaust (Hildebrandt et al., 2009; $\mathrm{Ng}$ et al., 2007; Presto et al., 2010; Tkacik et al., 2012). Therefore oxidation of the speciated precursors can explain the pre-LEV SOA data.

However, Fig. 7 indicates the effective yield for speciated precursors would need to be 32 and $128 \%$ to explain the median LEV1 and LEV2 experiments, respectively. This is much higher than the published yields for most speciated precursors at the relatively low organic aerosol concentrations $\left(<10 \mu \mathrm{g} \mathrm{m}^{-3}\right)$ inside the chamber (Table S1 in the Supplement). Therefore, it seems unlikely that the speciated precursors alone can explain the LEV1 and LEV2 chamber data. The only exceptions are one LEV1 and one LEV2 vehicle that had realistic (and repeatable) low yields.

Other studies report that speciated SOA precursors cannot explain the SOA formation from emissions from wood, diesel and jet fuel combustion (Weitkamp et al., 2007; Grieshop et al., 2009; Miracolo et al., 2011). SOA models based only on speciated precursors also systematically underpredict ambient SOA levels (de Gouw et al., 2005; Heald et al., 2005; Volkamer et al., 2006), especially in photochemical episodes (Vutukuru et al., 2006). Robinson et al. (2007) hypothesized that unspeciated, lower-volatility compounds are important SOA precursors. For example, Fig. 3 indicates that about $30 \%$ of the LEV1 and LEV2 NMOG emissions were not speciated (versus only $12 \%$ for the median preLEV vehicle). These unspeciated emissions are likely a combination of higher molecular weight or more polar species that were not quantified by the GC used in this study. This level of speciation is similar to previous studies (Schauer et al., 2002). Unspeciated NMOG emissions are not typically included in models and inventories.

To evaluate the potential contribution of the unspeciated NMOG to SOA formation, we calculated effective yield estimates accounting for both the speciated SOA precursors and unspeciated emissions. The reacted mass of the speciated precursors was calculated as described previously. To calculate the reacted mass of the unspeciated NMOG, we assumed that the unspeciated organics react with $\mathrm{OH}$ at $2 \times 10$ $11 \mathrm{~cm}^{3}$ molecule ${ }^{-1} \mathrm{~s}^{-1}$, which is representative of published kinetic data for large saturated alkanes (Atkinson and Arey, 2003). Figure 7 indicates that including unspeciated NMOG in the analysis reduces the effective yields to $1-2 \%$ for preLEV, 3-30\% for LEV1 and 3-46\% for LEV2. The LEV1 and LEV2 yields are reasonably consistent with data from single-compound smog chamber experiments (Hildebrandt et al., 2009; $\mathrm{Ng}$ et al., 2007; Presto et al., 2010; Tkacik et al., 2012), but the pre-LEV yields are on the low end of the single-compound data.

The effective yield analysis presented in Fig. 7 indicates that unspeciated NMOG emissions are an important class of precursors in LDGV emissions, especially for LEV1 and LEV2 vehicles. In fact, the oxidation of unspeciated NMOG emissions appears to contribute the majority of the SOA formation in the cold-start LEV1 and LEV2 experiments. Fur- thermore, the trends in effective yields plotted in Fig. 7 suggest that the mix of organic vapors emitted by newer vehicles was more efficient (higher yielding) in producing SOA than the emissions from older vehicles.

The effective yield estimates are sensitive to $\mathrm{OH}$ exposure and assumed reactivity for the unspeciated NMOG. Sensitivity analysis indicates that the combination of the uncertainty in $\mathrm{OH}$ exposure and reactivity could change the effective yields by a factor of 2 to 3 . However it is unlikely that this uncertainty would influence the relative trends in effective yields between different classes of vehicles.

\section{Discussion and conclusions}

To develop effective control strategies we must understand the overall contribution of emissions from motor vehicles to ambient PM - both primary particle emissions and secondary PM formed in the atmosphere. The primary PM and SOA data from these LDGV experiments are summarized in Fig. 8, which plots the median EC and POA emissions measured in the CVS and the median SOA formed in the smog chamber. The primary PM data shown in Fig. 6 constitute a subset (only the chamber vehicles) of the primary PM data in Fig. 8; therefore, medians in the two figures are not the same. The total height of the bars provides an estimate of the contribution of the emissions to different types of PM after $3 \mathrm{~h}$ of photooxidation. The median EC and POA values were calculated using the entire vehicle fleet $(63 \mathrm{LDGVs}$; May et al., 2014), while SOA medians are calculated from the subset of these vehicles used in chamber experiments. Data from the larger fleet shown in Fig. 2 indicate that LEV1 and LEV2 vehicles have similar primary PM emissions.

Figure 8 indicates that $3 \mathrm{~h}$ of photooxidation of LDGV dilute emissions in a smog chamber produced large amounts of SOA on both an absolute mass basis and in comparison to primary PM emissions. (This result and the qualitative patterns do not differ when SOA measured after equal $\mathrm{OH}$ exposure is used in Fig. 8 instead.) In fact, SOA formation from LDGV exhaust will likely exceed its direct contribution to ambient PM, especially for newer vehicles. During experiments with LEV1 and LEV2 LDGVs, the mass of SOA formed in the smog chamber was 3 to 4 times greater than the mass of primary PM emissions measured in the CVS. For the pre-LEV vehicles, the mass of SOA formed in the smog chamber was $\sim 75 \%$ greater than primary PM emissions. However, there was no evidence that SOA production was completed after $3 \mathrm{~h}$ of photooxidation (i.e., SOA was still being produced at the end of the experiments). Other studies have shown that SOA production downwind of urban areas may persist for $48 \mathrm{~h}$ (de Gouw et al., 2005, 2008). Therefore, the smog chamber data may underestimate the ultimate production of SOA from LDGV exhaust. This conclusion is qualitatively consistent with many ambient studies 


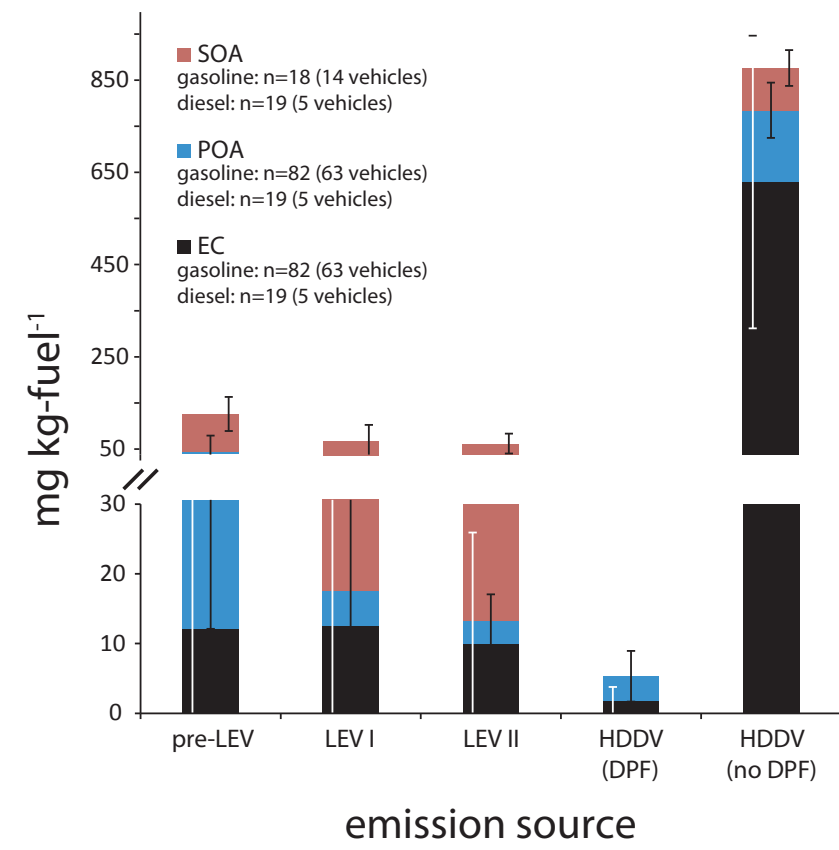

Fig. 8. Median EC, POA (in CVS) and SOA from light-duty gasoline vehicles (LDGVs) and heavy-duty diesel vehicles (HDDVs). LDGV data were obtained during cold-start UC driving cycle experiments with a single CA summertime gasoline. HDDV data were obtained during UDDS driving cycle experiments with 3 different types of ULSD fuel (Gordon et al., 2013a). Median SOA values are calculated from the averages obtained by applying the $\omega=0$ and $\omega=1$ wall-loss correction approaches. Error bars represent $\pm 1 \sigma$.

that report significant concentrations of SOA, even in urban areas (Jimenez et al., 2009).

Although tightening regulations have significantly reduced emissions of regulated primary pollutants (for example, Fig. 2 highlights the dramatic reductions in NMOG emissions from pre-LEV to LEV1 to LEV2 vehicles), the same may not be true for PM. In fact, Fig. 8 suggests that for LDGVs manufactured over the last 20 years (LEV1 and LEV2 vehicles) there may not have been much reduction in their contribution to ambient PM. This is not surprising; since LEV1 vehicles already met the LEV2 PM emissions standard, changes to engine control/aftertreatment from LEV1 to LEV2 were not aimed at reducing PM (or the nonvolatile particles - EC). Some fraction of semivolatile particles may be removed by the catalyst (note the downward trend in POA emissions in Fig. 2b), but the removal efficiency is not well understood.

Newer (LEV1 and LEV2) vehicles produced less SOA than older (pre-LEV) vehicles (per mass of fuel burned), but the differences were much smaller than the order of magnitude reduction in NMOG emissions. Therefore trends in SOA production appear to be more similar to the primary PM emissions than the NMOG emissions. This highlights the complex, nonlinear relationship between NMOG emis- sions and SOA formation, which is not surprising given that only a subset of the NMOG emissions are SOA precursors.

While further study will be required to fully elucidate the causes of the unexpected difference between the reductions of NMOG and SOA for the different LEV classes, we stress that this result is not due primarily to exogenous NMOG sources (e.g., from the transfer line or the propene used to adjust $\mathrm{VOC} / \mathrm{NO}_{\mathrm{x}}$ ratios) in our experiments. Control experiments in which the chamber was injected with (1) clean air instead of vehicle exhaust (i.e., dynamic blank experiments) and (2) exhaust from diesel vehicles emitting subambient (below the minimum detection limit of our instruments) particle and NMOG concentrations produced very little SOA, demonstrating that the SOA production observed during the chamber experiments was due to vehicle exhaust.

Several factors could explain the unexpected difference between the reductions of NMOG and SOA for the different LEV classes. In general, components of the vehicle system upstream (engine controls) and downstream (catalyst technologies) of the actual fuel combustion site play crucial roles in determining what is emitted from the tailpipe; thus, even when identical fuels are burned in different vehicles (as in the present study), there is no reason to expect that the emissions profiles should be identical.

Two changes to emission controls during the 1990s (i.e., between pre-LEV and LEV1) could have some impact on the specific NMOGs emitted by different vehicles: spark retard and catalyst formulation. Spark retard, first used extensively with LEV1 vehicles, was introduced to increase the catalyst warm-up rate, but this technique can change the mix of NMOGs emitted during the warm-up period (Lupescu, 2009; Russ, 1999). The higher temperature can lower the amount of unburned fuel released, but especially at extensive spark retard it can also increase the amount of partially burned fuel (potentially increasing the unspeciated fraction). In addition, during this same time period (pre-LEV to LEV1 transition) $\mathrm{Pd}$ began to replace $\mathrm{Pt}$ as the main active metal in automotive catalysts. This shift in control technology could also alter the mix of NMOGs emitted from newer vehicles (Kummer, 1975; McCabe, 1992). In particular, the catalytic capability of Pt and Pd may differ depending on whether or not the NMOGs have double bonds.

Furthermore, catalysts are optimized to reduce emissions of regulated pollutants $\left(\mathrm{NO}_{\mathrm{x}}, \mathrm{NMOG}\right.$, and $\left.\mathrm{CO}\right)$, not SOA precursors. Catalysts are typically developed using surrogate emissions comprised of small hydrocarbons, such as propene - many of which do not produce SOA in the atmosphere.

In addition to these two intrinsic differences (spark retard and catalyst formulation) among the vehicles studied, it is also possible that an artifact of our analysis could explain the difference between the reductions of NMOG and SOA for the different LEV classes. Our NMOG classification scheme (SOA precursor, nonprecursor, unspeciated) is coarse, and compounds within the SOA precursor class have a wide range of reaction rates 
with $\mathrm{OH}$ (minimum $k_{\mathrm{OH}}=1.14 \times 10^{-13}$, maximum $k_{\mathrm{OH}}=$ $5.8 \times 10^{-11} \mathrm{~cm}^{3}$ molecule $\mathrm{s}^{-1}$ ). Thus if among two vehicles with identical masses of SOA precursor emissions one vehicle's SOA precursor emissions include a larger share of compounds with fast reaction rates, that vehicle should have a greater yield than the other. To investigate this possibility, the emissions of individual NMOG species were plotted (pre-LEV vs. LEV1, LEV1 vs. LEV2 and pre-LEV vs. LEV2) on log-log axes in Fig. S6 in the Supplement. Points above (below) the trendlines in Fig. S6 in the Supplement indicate species that were reduced less (more) than the majority of the other species. Although a few species are biased above and below the trendlines, these are generally not relevant to first generation SOA production. For example, the clear outlier at $(x=5.27, y=1.39)$ in Fig. S6c in the Supplement represents propane. Important SOA precursors such as benzene and xylene are clustered around the trendline, indicating no bias. The absence of any clear bias from known SOA precursors supports the conclusion that the unexpectedly small reduction in SOA production for newer vehicles is due to photooxidation of unspeciated (presumably highmolecular-weight) compounds rather than those detected by the GC.

Much less SOA formation was measured in hot-start compared to cold-start tests. Therefore, catalyst warm-up appears to be an important factor in controlling the emissions of SOA precursors from LDGVs. But, again, the reductions in SOA formation during the hot-start tests were less than the reduction in NMOG emissions.

Figure 8 also compares the LDGV to hot-start experiments conducted as part of this project with three HDDVs (Gordon et al., 2013a). The lowest primary PM emissions and SOA formation were measured for the DPF-equipped HDDVs. Therefore, catalyzed DPFs appear to be a very effective control technology. The highest primary PM emissions and substantial SOA formation (comparable to the LDGVs on a fuel basis) were measured for non-DPF-equipped HDDVs. The primary PM emissions from the non-DPF-equipped diesels were mainly EC. Figure 8 presents the data from the perspective of an individual vehicle; in the United States there are substantially more LDGVs than HDDVs.

The conclusions in this work are based on smog chamber experiments. It is impossible to exactly reproduce atmospheric conditions inside a smog chamber; therefore, care must be exercised in extrapolating results from smog chamber experiments to the atmosphere. For example, it is not appropriate to simply translate the wall-loss-corrected concentrations plotted in Fig. 5 to the atmosphere. The major goals of these experiments were to quantify the fraction of LDGV emissions (yield) that form SOA and to assess the relative importance of primary PM emissions versus SOA formation.

The experiments were designed to investigate relatively fresh SOA, similar to what might be formed in urban environments (modest $\mathrm{OH}$ exposures, relatively high $\mathrm{NO}_{\mathrm{x}}$, and moderate organic aerosol concentrations). This was done by matching key parameters known to strongly influence SOA production, such as $\mathrm{PM}$ concentrations and $\mathrm{VOC} / \mathrm{NO}_{\mathrm{x}}$ ratios, to urban-like values. For example, PM levels inside the chamber were maintained between 2 and $20 \mu \mathrm{g} \mathrm{m}^{-3}$; therefore, gas-particle partitioning of semivolatile organics should be similar to that found in urban settings. We also added propene (which is not a SOA precursor; Kroll and Seinfeld, 2008 ) to the chamber to adjust the $\mathrm{VOC} / \mathrm{NO}_{\mathrm{x}}$ ratio to match a typical urban level $\sim 3: 1 \mathrm{ppbC}_{\mathrm{ppbNO}}^{-1}$. This helps ensure that the important radical branching channels such as the fate of organoperoxy radicals $\left(\mathrm{RO}_{2}\right)$ are similar to those in the atmosphere (Presto et al., 2005; Lim and Ziemann, 2009; $\mathrm{Ng}$ et al., 2007). However, other parameters were outside typical atmospheric ranges. Mixing ratios of individual organic gases and $\mathrm{NO}_{\mathrm{x}}$ were generally higher than typical urban levels, and the mix of organics inside the chamber (gasoline exhaust + propene) was different than that in the atmosphere. Fortunately, SOA yields are thought to be less sensitive to absolute concentrations, especially if the organic aerosol levels in the chamber are atmospherically relevant. To the extent that the product distribution of the organic oxidation reactions differs from the atmosphere, these differences will influence SOA formation.

Except for the oldest (pre-LEV) vehicles, SOA production could not be fully explained by speciated (traditional) SOA precursors. However, about $30 \%$ of the NMOG emissions from LEV1 and LEV2 vehicles could not be speciated. These unspeciated emissions appear to be important SOA precursors, likely forming the majority of the SOA in experiments performed with LEV1 and LEV2 vehicles. Given the unexpected finding that the gas-phase emissions from newer, LEV2 vehicles are more efficient at producing SOA than emissions from older, pre-LEV vehicles, future studies elucidating the nature of these precursors are needed to advance the development of next-generation SOA models and emissions control strategies.

\section{Supplementary material related to this article is available online at http://www.atmos-chem-phys.net/14/ 4661/2014/acp-14-4661-2014-supplement.pdf.}

Acknowledgements. This research would not have been possible without the hard work of the excellent and dedicated staff at the California Air Resources Board's Haagen-Smit Laboratory. Funding was provided by the US Environmental Protection Agency National Center for Environmental Research (NCER) through the STAR program (R833748), the National Science Foundation's Graduate Research Fellowship Program and the Coordinating Research Council through project no. A-74/E-96. The California Air Resources Board provided significant in-kind support, including vehicle recruitment, vehicle testing, and sample analysis. The views, opinions, and/or findings contained in this paper are those of the authors and should not be construed as an official position of the funding agencies. 
Edited by: L. M. Russell

\section{References}

Allan, J. D., Delia, A. E., Coe, H., Bower, K. N., Alfarra, M. R., Jimenez, J. L., Middlebrook, A. M., Drewnick, F., Onasch, T. B., and Canagaratna, M. R.: A generalised method for the extraction of chemically resolved mass spectra from Aerodyne aerosol mass spectrometer data, J. Aerosol Sci., 35, 909-922, 2004.

Atkinson, R. and Arey, J.: Atmospheric degradation of volatile organic compounds, Chem. Rev., 103, 4605-4638, 2003.

California Air Resources Board: S.O.P. MLD 119: Procedure for the Direct Determination of Total Non-Methane Hydrocarbons and Methane in Motor Vehicle Exhaust Using Cryogenic Preconcentration and Flame Ionization Detection, http://www.arb.ca.gov/ testmeth/slb/sop119.pdf (last access: 14 April 2014), 2001.

California Air Resources Board: S.O.P. MLD 102/103: Procedure For The Determination Of $\mathrm{C}_{2}$ To $\mathrm{C}_{12}$ Hydrocarbons In Automotive Exhaust Samples By Gas Chromatography, http://www.arb. ca.gov/testmeth/slb/sop102-103v2-2.pdf (last access: 14 April 2014), 2004.

California Air Resources Board: S.O.P. MLD 104: Determination of Aldehyde and KetoneCompounds in Automotive Source Samples by High Performance Liquid Chromatography, www.arb. ca.gov/testmeth/slb/sop104v3.pdf (last access: 14 April 2014), 2006.

Chirico, R., DeCarlo, P. F., Heringa, M. F., Tritscher, T., Richter, R., Prévôt, A. S. H., Dommen, J., Weingartner, E., Wehrle, G., Gysel, M., Laborde, M., and Baltensperger, U.: Impact of aftertreatment devices on primary emissions and secondary organic aerosol formation potential from in-use diesel vehicles: results from smog chamber experiments, Atmos. Chem. Phys., 10, 11545-11563, doi:10.5194/acp-10-11545-2010, 2010.

Chow, J., Watson, J., Pritchett, L., Pierson, W., Frazier, C., and Purcell, R.: The DRI thermal optical reflectance carbon analysis system - description, evaluation and applications in UnitedStates air quality studies, Atmos. Environ. A-Gen., 27, 11851201, 1993.

de Gouw, J., Brock, C., Atlas, E., Bates, T., Fehsenfeld, F., Goldan, P., Holloway, J., Kuster, W., Lerner, B., and Matthew, B.: Sources of particulate matter in the northeastern United States in summer: 1. Direct emissions and secondary formation of organic matter in urban plumes, J. Geophys. Res., 113, D08301, doi:10.1029/2007JD009243, 2008.

de Gouw, J. A., Middlebrook, A. M., Warneke, C., Goldan, P. D., Kuster, W. C., Roberts, J. M., Fehsenfeld, F. C., Worsnop, D. R., Canagaratna, M. R., Pszenny, A. A. P., Keene, W. C., Marchewka, M., Bertman, S. B., and Bates, T. S.: Budget of organic carbon in a polluted atmosphere: Results from the New England Air Quality Study in 2002, J. Geophys. Res., 110, D16305, doi:10.1029/2004JD005623, 2005.

Donahue, N., Robinson, A., Stanier, C., and Pandis, S.: Coupled partitioning, dilution, and chemical aging of semivolatile organics, Environ. Sci. Technol., 40, 2635-2643, 2006.

Dua, S., Hopke, P., and Raunemaa, T.: Hygroscopicity of diesel aerosols, Water Air Soil Pollut., 112, 247-257, 1999.

Farmer, D., Matsunaga, A., Docherty, K., Surratt, J., Seinfeld, J., Ziemann, P., and Jimenez, J.: Response of an aerosol mass spectrometer to organonitrates and organosulfates and implications for atmospheric chemistry, P. Natl. Acad. Sci., 107, 6670-6675, doi:10.1073/pnas.0912340107, 2010.

Gordon, T. D., Presto, A. A., Nguyen, N. T., Robertson, W. H., Na, K., Sahay, M., Zhang, M., Maddox, C., Rieger, P., Chattopadhyay, S., Maldonado, H., Maricq, M., and Robinson, A. L.: Secondary Organic Aerosol Production from Diesel Vehicle Exhaust: Impact of Aftertreatment, Fuel Chemistry and Driving Cycle, Atmos. Chem. Phys. Discuss., 13, 24223-24262, doi:10.5194/acpd-13-24223-2013, 2013a.

Gordon, T. D., Tkacik, D. S., Presto, A. A., Zhang, M., Jathar, S. H., Nguyen, N. T., Massetti, J., Truong, T., Cicero-Fernandez, P., Maddox, C., Rieger, P., Chattopadhyay, S., Maldonado, H., Maricq, M. M., and Robinson, A. L.: Primary Gas- and ParticlePhase Emissions and Secondary Organic Aerosol Production from Gasoline and Diesel Off-Road Engines, Environ. Sci. Technol., 47 14137-14146, 2013b.

Grieshop, A. P., Logue, J. M., Donahue, N. M., and Robinson, A. L.: Laboratory investigation of photochemical oxidation of organic aerosol from wood fires 1: measurement and simulation of organic aerosol evolution, Atmos. Chem. Phys., 9, 1263-1277, doi:10.5194/acp-9-1263-2009, 2009.

Heald, C. L., Jacob, D. J., Park, R. J., Russell, L. M., Huebert, B. J., Seinfeld, J. H., Liao, H., and Weber, R. J.: A large organic aerosol source in the free troposphere missing from current models, Geophys. Res. Lett., 32, 1-4, 2005.

Hennigan, C. J., Miracolo, M. A., Engelhart, G. J., May, A. A., Presto, A. A., Lee, T., Sullivan, A. P., McMeeking, G. R., Coe, H., Wold, C. E., Hao, W.-M., Gilman, J. B., Kuster, W. C., de Gouw, J., Schichtel, B. A., Collett Jr., J. L., Kreidenweis, S. M., and Robinson, A. L.: Chemical and physical transformations of organic aerosol from the photo-oxidation of open biomass burning emissions in an environmental chamber, Atmos. Chem. Phys., 11, 7669-7686, doi:10.5194/acp-11-7669-2011, 2011.

Hildebrandt, L., Donahue, N. M., and Pandis, S. N.: High formation of secondary organic aerosol from the photo-oxidation of toluene, Atmos. Chem. Phys., 9, 2973-2986, doi:10.5194/acp-92973-2009, 2009.

Jathar, S. H., Miracolo, M. A., Tkacik, D. S., Adams, P. J., and Robinson, A. L.: Secondary organic aerosol from photooxidation of evaporated fuel: Experimental results and implications for aerosol formation from combustion emissions, Environ. Sci. Technol., 47, 12886-12893, 2013.

Jimenez, J. L., Canagaratna, M. R., Donahue, N. M., Prevot, A. S. H., Zhang, Q., Kroll, J. H., DeCarlo, P. F., Allan, J. D., Coe, H., Ng, N. L., Aiken, A. C., Docherty, K. S., Ulbrich, I. M., Grieshop, A. P., Robinson, A. L., Duplissy, J., Smith, J. D., Wilson, K. R., Lanz, V. A., Hueglin, C., Sun, Y. L., Tian, J., Laaksonen, A., Raatikainen, T., Rautiainen, J., Vaattovaara, P., Ehn, M., Kulmala, M., Tomlinson, J. M., Collins, D. R., Cubison, M. J., E., Dunlea, J., Huffman, J. A., Onasch, T. B., Alfarra, M. R., Williams, P. I., Bower, K., Kondo, Y., Schneider, J., Drewnick, F., Borrmann, S., Weimer, S., Demerjian, K., Salcedo, D., Cottrell, L., Griffin, R., Takami, A., Miyoshi, T., Hatakeyama, S., Shimono, A., Sun, J. Y., Zhang, Y. M., Dzepina, K., Kimmel, J. R., Sueper, D., Jayne, J. T., Herndon, S. C., Trimborn, A. M., Williams, L. R., Wood, E. C., Middlebrook, A. M., Kolb, C. E., Baltensperger, U., and Worsnop, D. R.: Evolution of Organic Aerosols in the Atmosphere, Science, 326, 1525-1529, doi:10.1126/science.1180353, 2009. 
Kanakidou, M., Seinfeld, J. H., Pandis, S. N., Barnes, I., Dentener, F. J., Facchini, M. C., Van Dingenen, R., Ervens, B., Nenes, A., Nielsen, C. J., Swietlicki, E., Putaud, J. P., Balkanski, Y., Fuzzi, S., Horth, J., Moortgat, G. K., Winterhalter, R., Myhre, C. E. L., Tsigaridis, K., Vignati, E., Stephanou, E. G., and Wilson, J.: Organic aerosol and global climate modelling: a review, Atmos. Chem. Phys., 5, 1053-1123, doi:10.5194/acp-5-1053-2005, 2005.

Kirchstetter, T. W. and Novakov, T.: Controlled generation of black carbon particles from a diffusion flame and applications in evaluating black carbon measurement methods, Atmos. Environ., 41, 1874-1888, 2007.

Kroll, J. H. and Seinfeld, J. H.: Chemistry of secondary organic aerosol: Formation and evolution of low-volatility organics in the atmosphere, Atmos. Environ., 42, 3593-3624, doi:10.1016/j.atmosenv.2008.01.003, 2008.

Kummer, J.: Oxidation of $\mathrm{CO}$ and $\mathrm{C} 2 \mathrm{H} 4$ by base metal catalysts prepared on honeycomb supports. Adv. Chem. Ser., 143, p. 178, 1975.

Lambe, A. T., Onasch, T. B., Croasdale, D. R., Wright, J. P., Martin, A. T., Franklin, J. P., Massoli, P., Kroll, 5 J. H., Canagaratna, M. R., and Brune, W. H.: Transitions from functionalization to fragmentation reactions of laboratory secondary organic aerosol (SOA) generated from the $\mathrm{OH}$ oxidation of alkane precursors, Environ. Sci. Technol., 46, 5430-5437, 2012.

Lim, Y. B. and Ziemann, P. J.: Chemistry of Secondary Organic Aerosol Formation from $\mathrm{OH}$ Radical-Initiated Reactions of Linear, Branched, and Cyclic Alkanes in the Presence of $\mathrm{NO}_{\mathrm{x}}$, Aerosol Sci. Technol., 43, 604-619, doi:10.1080/02786820902802567, 2009.

Lipsky, E. M. and Robinson, A. L.: Effects of Dilution on Fine Particle Mass and Partitioning of Semivolatile Organics in Diesel Exhaust and Wood Smoke, Environ. Sci. Technol., 40, 155-162, doi:10.1021/es050319p, 2006.

Lupescu J. A., Chanko T. B., Richert J. F., and Mauti, A. A.: The Effect of Spark Timing on Engine-Out Hydrocarbon Speciation and Hydrocarbon Trap Performance. SAE Int., 01-1068, 2009.

Maricq, M. M., Chase, R. E., Podsiadlik, D. H., and Vogt, R.: Vehicle exhaust particle size distributions: a comparison of tailpipe and dilution tunnel measurements, SAE Transactions, 108, 721$732,1999$.

Matsunaga, A. and Ziemann, P. J.: Gas-Wall Partitioning of Organic Compounds in a Teflon Film Chamber and Potential Effects on Reaction Product and Aerosol Yield Measurements, Aerosol Sci. Technol., 44, 881-892, doi:10.1080/02786826.2010.501044, 2010.

May, A. A., Presto, A. A., Hennigan, C. J., Nguyen, N. T., Gordon, T. D., and Robinson, A. L.: Gas-Particle Partitioning of Primary Organic Aerosol Emissions: (2) Diesel Vehicles, Environ. Sci. Technol., 47, 8288-8296, doi:10.1021/es400782j, 2013a.

May, A. A., Presto, A. A., Hennigan, C. J., Nguyen, N. T., Gordon, T. D., and Robinson, A. L.: Gas-particle partitioning of primary organic aerosol emissions: (1) Gasoline vehicle exhaust, Atmos. Environ., 77, 128-139, doi:10.1016/j.atmosenv.2013.04.060, 2013b.

May, A. A., Nguyen, N. T., Presto, A. A., Gordon, T. D., Lipsky, E. M., Karve, M., Gutierrez, A., Zhang, M., Pang, Y., Huang, S., Fuentes, M., Vo, T., McCauley, E., Sax, T., Cicero-Fernandez, P., Massetti, J., Chen, S., Truong, T., Na, K., Long, J., Chang,
O., Robertson, W. H., Rieger, P., Ling, R., Maddox, C., Chattopadhyay, S., Maldonado, H., Maricq, M. M., and Robinson, A. L.: Gas- and particle-phase primary emissions from in-use, onroad gasoline and diesel vehicles, Atmos. Environ., 88, 247-260, doi:10.1016/j.atmosenv.2014.01.046, 2014.

McCabe, R. W., Siegl, W. O., Chun, W., and Perry, J.: Speciated Hydrocarbon Emissions from the Combustion of Single Component Fuels. II. Catalyst Effects. J. Air Waste Manage. Assoc., 42, 1071-1077, 1992.

McMurry, P. H. and Grosjean, D.: Gas and aerosol wall losses in Teflon film smog chambers, Environ. Sci. Technol., 19, 11761182, doi:10.1021/es00142a006, 1985.

Miracolo, M. A., Presto, A. A., Lambe, A. T., Hennigan, C. J., Donahue, N. M., Kroll, J. H., Worsnop, D. R., and Robinson, A. L.: Photo-Oxidation of Low-Volatility Organics Found in Motor Vehicle Emissions: Production and Chemical Evolution of Organic Aerosol Mass, Environ. Sci. Technol., 44, 1638-1643, doi:10.1021/es902635c, 2010.

Miracolo, M. A., Hennigan, C. J., 5 Ranjan, M., Nguyen, N. T., Gordon, T. D., Lipsky, E. M., Presto, A. A., Donahue, N. M., and Robinson, A. L.: Secondary aerosol formation from photochemical aging of aircraft exhaust in a smog chamber, Atmos. Chem. Phys., 11, 4135-4147, doi:10.5194/acp-11-4135-2011, 2011.

Ng, N. L., Kroll, J. H., Chan, A. W. H., Chhabra, P. S., Flagan, R. C., and Seinfeld, J. H.: Secondary organic aerosol formation from $m$-xylene, toluene, and benzene, Atmos. Chem. Phys., 7, 3909-3922, doi:10.5194/acp-7-3909-2007, 2007.

Nordin, E. Z., Eriksson, A. C., Roldin, P., Nilsson, P. T., Carlsson, J. E., Kajos, M. K., Hellén, H., Wittbom, C., Rissler, J., Löndahl, J., Swietlicki, E., Svenningsson, B., Bohgard, M., Kulmala, M., Hallquist, M., and Pagels, J. H.: Secondary organic aerosol formation from idling gasoline passenger vehicle emissions investigated in a smog chamber, Atmos. Chem. Phys., 13, 6101-6116, doi:10.5194/acp-13-6101-2013, 2013.

Odum, J. R., Hoffmann, T., Bowman, F., Collins, D., Flagan, R. C., and Seinfeld, J. H.: Gas/Particle Partitioning and Secondary Organic Aerosol Yields, Environ. Sci. Technol., 30, 2580-2585, doi:10.1021/es950943, 1996.

Pisano, J., Durbin, T., Karavalakis, G., Collins, T., Huai, T., Ayala, A., Cicero-Fernandez, P., Zhang, M., Gutierrez, A., Huo, D., and Vo, T.: Characterization of PM and PM Instruments for High Emitting Light-Duty Gasoline Vehicles, SAE paper, 01, 2011.

Platt, S. M., El Haddad, I., Zardini, A. A., Clairotte, M., Astorga, C., Wolf, R., Slowik, J. G., Temime-Roussel, B., Marchand, N., Ježek, I., Drinovec, L., Močnik, G., Möhler, O., Richter, R., Barmet, P., Bianchi, F., Baltensperger, U., and Prévôt, A. S. H.: Secondary organic aerosol formation from gasoline vehicle emissions in a new mobile environmental reaction chamber, Atmos. Chem. Phys., 13, 9141-9158, doi:10.5194/acp-13-91412013, 2013.

Presto, A. A., Huff Hartz, K. E., and Donahue, N. M.: Secondary Organic Aerosol Production from Terpene Ozonolysis. 2. Effect of $\mathrm{NO}_{\mathrm{x}}$ Concentration, Environ. Sci. Technol., 39, 7046-7054, doi:10.1021/es050400s, 2005.

Presto, A. A., Miracolo, M. A., Donahue, N. M., and Robinson, A. L.: Secondary Organic Aerosol Formation from High-NO Photo-Oxidation of Low Volatility Precursors: n-Alkanes, Environ. Sci. Technol., 44, 2029-2034, doi:10.1021/es903712r, 2010. 
Robert, M. A., VanBergen, S., Kleeman, M. J., and Jakober, C. A.: Size and composition distributions of particulate matter emissions: part 1 - light-duty gasoline vehicles, J. Air Waste Manage., 57, 1414-1428, 2007.

Robinson, A. L., Donahue, N. M., Shrivastava, M. K., Weitkamp, E. A., Sage, A. M., Grieshop, A. P., Lane, T. E., Pierce, J. R., and Pandis, S. N.: Rethinking organic aerosols: Semivolatile emissions and photochemical aging, Science, 315, 1259-1262, doi:10.1126/science.1133061, 2007.

Russ, S., Thiel, M., and Lavoie, G.:SI engine operation with retarded ignition: Part 2-HC emissions and oxidation, SAE Trans., 108, 1532-1538, 1999.

Samy, S. and Zielinska, B.: Secondary organic aerosol production from modern diesel engine emissions, Atmos. Chem. Phys., 10, 609-625, doi:10.5194/acp-10-609-2010, 2010.

Schauer, J. J., Kleeman, M. J., Cass, G. R., and Simoneit, B. R. T.: Measurement of Emissions from Air Pollution Sources. 2. $\mathrm{C}_{1}$ through $\mathrm{C}_{30}$ Organic Compounds from Medium Duty Diesel Trucks, Environ. Sci. Technol., 33, 1578-1587, doi:10.1021/es980081n, 1999.

Schauer, J. J., Kleeman, M. J., Cass, G. R., and Simoneit, B. R. T.: Measurement of Emissions from Air Pollution Sources. 5. $\mathrm{C}_{1}-\mathrm{C}_{32}$ Organic Compounds from GasolinePowered Motor Vehicles, Environ. Sci. Technol., 36, 1169-1180, doi:10.1021/es0108077, 2002.

Seinfeld, J. and Pandis, S. N.: From air pollution to climate change, Atmospheric Chemistry and Physics, 2nd Edn., p. 208, 1998.

Stone, E. A., Zhou, J., Snyder, D. C., Rutter, A. P., Mieritz, M., and Schauer, J. J.: A Comparison of Summertime Secondary Organic Aerosol Source Contributions at Contrasting Urban Locations, Environ. Sci. Technol., 43, 3448-3454, doi:10.1021/es8025209, 2009.
Subramanian, R., Donahue, N. M., Bernardo-Bricker, A., Rogge, W. F., and Robinson, A. L.: Insights into the primary-secondary and regional-local contributions to organic aerosol and $\mathrm{PM}_{2.5}$ mass in Pittsburgh, Pennsylvania, Atmos. Environ., 41, 74147433, doi:10.1016/j.atmosenv.2007.05.058, 2007.

Tkacik, D. S., Presto, A. A., Donahue, N. M., and Robinson, A. L.: Secondary organic aerosol formation from intermediatevolatility organic compounds: cyclic, linear, and branched alkanes, Environ. Sci. Technol., 46, 8773-8781, 2012.

Turpin, B. J., Saxena, P., and Andrews, E.: Measuring and simulating particulate organics in the atmosphere: problems and prospects, Atmos. Environ., 34, 2983-3013, doi:10.1016/s13522310(99)00501-4, 2000.

Volkamer, R., Jimenez, J. L., San Martini, F., Dzepina, K., Zhang, Q., Salcedo, D., Molina, L. T., Worsnop, D. R., and Molina, M. J.: Secondary organic aerosol formation from anthro- pogenic air pollution: Rapid and higher than expected, Geophys. Res. Lett., 33, L17811, doi:10.1029/2006GL026899, 2006.

Vutukuru, S., Griffin, R. J., and Dabdub, D.: Simulation and analysis of secondary organic aerosol dynamics in the South Coast Air Basin of California, J. Geophys. Res., 111, D10S12, doi:10.1029/2005JD006139, 2006.

Weingartner, E., Burtscher, H., and Baltensperger, U.: Hygroscopic properties of carbon and diesel soot particles, Atmos. Environ., 31, 2311-2327, 1997.

Weitkamp, E., Sage, A., Pierce, J., Donahue, N., and Robinson, A.: Organic Aerosol Formation from Photochemical Oxidation of Diesel Exhaust in a Smog Chamber, Environ. Sci. Technol., 41, 6969-6975, 2007. 